\title{
FEMINISMO, PRENSA Y SOCIEDAD EN ESPAÑA *
}

\author{
M. Isabel Marrades
}

Este artículo es un estudio sobre las revistas femeninas en España desde el siglo xviII hasta la guerra civil. En él se analiza la orientación ideológica de cada revista, la personalidad de las colaboradoras y el contexto social en que se publicaban. Prácticamente todas las revistas femeninas que aparecen en España durante este período han sido incluidas en este estudio, lo que le da el carácter de un análisis exhaustivo sobre el tema. Al mismo tiempo permite ver la evolución y el cambio de la prensa femenina de España desde su nacimiento hasta la guerra civil.

* Este artículo forma parte de un estudio más amplio que sobre la imagen de la mujer en la prensa femenina española están realizando $M$. Isabel Marrades y Adolfo Perinat gracias a una beca de: la Editorial Aguilar. 
No puede calificarse ni de importante ni de larga la tradición del periodismo femenino en España. Tiene, con todo, unos comienzos curiosos y una historia interesante y agitada. Las huellas más lejanas de una actividad femenina dentro de la prensa se sitúan en el siglo xvir. Una cierta Francisca de Aculodi, de San Sebastián, «impresora de esta noble y leal provincia de Guipúzcoa», inició, entre 1687 y 1689, la publicación de una hoja intitulada Noticias principales y verdaderas. Aparecía cada quince días y era la reproducción de un periódico escrito en lengua castellana en Bruselas, capital por aquel entonces de los dominios españoles de Flandes. Francisca de Aculodi incluía además noticias locales que ella misma recogía y escribía, y alcanzó, según indicios, cierta fama. ${ }^{1}$

Pasan los años y hay que esperar a la segunda mitad del siglo xvinI para que vea la luz la primera publicación periódica que podemos clasificar como «femenina». Se trata de La Pensadora Gaditana, de la cual en seguida hablaremos. Según el historiador de la prensa española Gómez Aparicio, por estas fechas se acaba aquella primera forma de periodismo tradicional, espontáneo y artesano, y empieza a organizarse lo que más tarde se ha venido a llamar «el cuarto poder». La función crítica de las publicaciones periódicas es, desde aquel entonces, bien patente en la sociedad, e incluso apuntan los primeros brotes de una prensa revolucionaria. Durante el siglo y medio largo que transcurre desde el ocaso de la Ilustración hasta la Guerra Civil, las publicaciones periódicas españolas serán un reflejo fiel de las situaciones políticas por que atraviesa el país. Siempre y cuando tengan derecho a la existencia, porque ellas son las primeras en sufrir las consecuencias del talante de los gobiennos y su mensaje oscila dramáticamente entre la libertad total y la censura más estricta. Esto que decimos de la prensa en general es también aplicable a la prensa femenina.

En 1762 el rey Carlos III quiso que la prensa se convirtiese en un

1. Pedro Gómez Aparicio, Historia del periodismo español (Madrid: Ed. Nacional, 1967), p. 159. 
instrumento de educación popular y suprimió, mediante Real Orden, los obstáculos que se oponían a su desarrollo, tales como reglamentos, autorizaciones previas, privilegios de corrección, leyes de censura y otras complicaciones que concurrían a hacer difícil la publicación de un periódico. Por otra parte, desde los comienzos de su reinado manifestó preocupación por mejorar la educación de las mujeres, y así, al crearse la Sociedad Económica Madrileña de Amigos del País, autorizó que fueran admitidas en ella 14 mujeres de la alta sociedad.

El rey entiende que la admisión de socias de mérito y honor, que en Juntas regulares y separadas traten de los mejores medios de promover la virtud, la aplicación y la industria en su sexo, sería muy conveniente en la Corte, y que escogiendo las que por sus circunstancias sean más acreedoras a esta honrosa distinción, procedan y traten unidas los medios de fomentar la buena educación, mejorar las costumbres con sus ejemplos y escritos, introducir el amor al trabajo, cortar el lujo que al paso destruye las fortunas de los particulares, retrae muchos del matrimonio, en perjuicio del Estado, y sustituir para sus adornos los nacionales a los extranjeros y de cuyo capricho, S.M. se lisonjea de que ya se vieron tantas damas honrar antiguamente su Monarquía, con el talento que caracteriza a las españolas, seguirán estos generosos ejemplos y que resultarán de sus Juntas tantas o mayores ventajas que las que se ven con singular complacencia de su real ánimo paterno, producirse por medio de las Juntas Económicas de su reino...2

Poco después y por primera vez en la historia de la Universidad española, una mujer obtuvo el grado de doctor en Filosofía y Letras, y fue recibida en la Real Academia Española.

Hay que educar a la mujer, dice el rey paternalmente, a fin de hacerla capaz de participar en la política económica del país, sacarla de su ociosidad y frivolidad, que favorecen el despilfarro y los gastos sin medida, para seguir la moda, y que arruinan a maridos y amantes. Quizá se llegará así a reconciliar al hombre con el matrimonio que va perdiendo cada día más su prestigio, como lo revelan ciertos manuscritos clandestinos que circulaban exaltando el divorcio como remedio para todos los males. ${ }^{3}$

2. Carmen Martín Gaite, Usos amorosos del dieciocbo en España (Madrid: Siglo XXI, 1972), p. 128.

3. Ibid. 
Estos hechos, así como la ley que autorizó a las mujeres y las niñas el aprender un oficio, caracterizan una época en la que es patente la tendencia general a considerar la incorporación de la mujer al trabajo para el bien de la comunidad. En realidad, esta medida que legalizaba su trabajo (aun cuando lo estuvieran realizando desde hacía tiempo) refleja un cambio en los roles familiares en cuanto que refrenda el hecho de que el padre ya no es el único sostén de la familia. Por otra parte, ello concurre al servicio de los intereses de la naciente inctustria, que remuneraba el trabajo de la mujer y de los niños muy por debajo del del varón. Como consecuencia, hay una desvalorización de la mano de obra y los hombres, por primera vez en la historia, sufren la competencia de las mujeres en un terreno que hasta entonces les estaba reservado.

Por desgracia, no han llegado (si los hubo) hasta nosotros periódicos femeninos de la época que nos den testimonios más directos, y tampoco sabemos apenas qué es lo que leían aquellas damas elegantes, ligeras y frágiles, que podían salir a paseo con una cierta libertad, ir al teatro (siempre al sitio reservado para ellas), y que sabían divertirse bastante bien. Se ha dicho que el siglo xvirl descubrió a la mujer «adorno», luego de haberla considerado anteriormente como «instrumento». Comenzaron a ponerse en boga las modas francesas, y de París provenían las prendas más lujosas. Pero también se imitaban las costumbres populares: las maneras un tanto bruscas, al par que alegres, vibrantes y espontáneas de los «majos» y «manolas» eran consideradas como graciosas y llenas de encanto. Algunas de estas informaciones nos han sido transmitidas por Nipho, un periodista que introdujo en España la prensa semanal y que publicó una adaptación de L'Ami des femmes de Mirabeau. ${ }^{4}$

El único periódico femenino de la época que hemos podido encontrar, que es también el primero en su género, se caracteriza por la extraordinaria originalidad de su contenido y la agudeza de su autora. Es asimismo el primero que posee un cierto carácter feminista. Nos referimos a La Pensadora Gaditana, que se publicaba en Madrid y en Cádiz en 1768, y que firmaba una tal Beatriz Cienfuegos. Ella escribía cada semana un discurso moral de 24 páginas relacionado con las costumbres de las mujeres de su tiempo. Su intención, dice, era la de criticar y hacer ridículos los muchos vicios que con «capa de estilo y brillantez remarcable, se han introducido entre nosotros».

Este periódico nació como reacción contra los excesos de un famoso

4. «En 1801 este libro fue prohibido por la Inquisición por ser difícil de expurgar y porque puede abrir los ojos a los jóvenes.» Martín Gaite, op. cit., p. 49. 
periodista de la época, Clavijo y Fajardo, que escribía en contra de las mujeres en un periódico denominado El Pensador. Beatriz Cienfuegos dice cómo se lanzó a tomar la pluma:

Exaltado todo el humor colérico de mi natural con las desatenciones, groserías y atrevimientos del señor de El Pensador de Madrid. Alguna vez había de llegar la ocasión en que se viesen Catones sin barbas y Licurgos con basquiñas. No ha de estar siempre ceñido el don de dar consejo a las pelucas, ...también los mantos tienen su alma, su entendimiento y su razón. Pues que los hombres han de mandar, han de reñir, han de gobernar y corregir, y a las pobrecitas mujeres, engañadas con el falso oropel de hermosas y damas, sólo se les han de permitir gajes de rendimientos fingidos... y acabándose la comedia de la pretensión, todo se oculta, y ¿sólo se descubre el engaño y la falsedad? No, señores míos, hoy quiero, disponiendo el encogimiento propio de mi sexo, dar leyes, corregir abusos, reprender ridiculeces y pensar como vuestras mercedes piensan, pues, aunque atropelle nuestra antigua condición, que es siempre ser hipócritas de pensamientos, los he de echar a volar para que vea el mundo a una mujer que piensa con reflexión, amonesta con madurez y critica con chiste. ${ }^{5}$

Beatriz Cienfuegos supo hacer todo esto en un estilo muy sencillo y espontáneo, con la audacia de una mujer libre que busca cómo expresarse en un momento en que todos los caminos están bloqueados:

Mi inclinación es la libertad de una vida sin la sujeción penosa del matrimonio, ni la esclavitud vitalicia de un encierro.

Sus discursos no se dirigen sólo a las mujeres, sino a todos los ociosos y a los privilegiados:

¿Qué derecho te ha dado este fingido honor de que haces alarde, para que usurpes a los pobres y les comas las dulces cosechas de sus industrias? ${ }^{6}$

Tanta osadía le acarreó no pocas complicaciones. Ella misma nos lo dice en su último periódico o «pensamiento»:

5. La Pensadora Gaditana. Pensamiento I.

6. Ibid. Pensamiento IV. 
Me hallo tan ofuscada de abusos, preocupaciones y críticas, que contra mi natural mismo me he convertido en hiel y vinagre, siendo antes de un genio más dulce que la miel.

No se sabe gran cosa sobre esta mujer. Ni siquiera se ha encontrado su nombre en los registros de bautismo gaditanos. Probablemente utilizó un pseudónimo. Otros rumores se hicieron eco de que quizá no era una mujer, que sólo un hombre podía poseer un estilo tan brillante. A lo cual ella responde con desenfado:

Porque todos porfían, y a su parecer con razón, de que no es mujer la Pensadora: hay tal ignorancia. ¿Dios ha dado a las mujeres otra alma distinta, y de menos facultades que la del hombre? o ¿procuran hacer valer aquella antigua y errada opinión, de que las mujeres eran animales imperfectos, extendiéndola también a sus luces, a sus discursos y a su entendimiento?... Desengáñense Uds., mujer soy, y mujer que tal cual puede discurrir, y ojalá que me fuera posible dejar de serlo, para de este modo alejarme cuanto pudiera de un sexo, que tan poco procura su esplendor...7

Toda mujer sabía que firmar con su propio nombre era arriesgarse al escándalo y al ludibrio; demostrar una cierta cultura era asimismo exponerse al ridículo y a ser mal vista por las mujeres de aquella sociedad. En su prólogo, el primer «pensamiento» de esta publicación, Beatriz Cienfuegos nos da el retrato de su persona:

Yo, señores, gozo de la suerte de ser hija de Cádiz, bastante he dicho para poder hablar sin vergüenza. Mis padres desde pequeña me inclinaron a monja, pero yo siempre dilaté la ejecución: ellos porfiaron, y para conseguir el fin de sus intentos me enseñaron el manejo de los libros y formaron en mí el buen gusto de las letras para lo que, dándome maestros, con alguna aplicación mía me impusieron en la latinidad. Sé hacer un silogismo y no ignoro que la materia primera no puede existir sin la forma, con estas bachillerías y seis años de reclusión en un convento, he salido tan teóloga que todos en mi casa me veneran por una sibila. $^{8}$

7. Ibid. Pensamiento III.

8. Ibid. Pensamiento VIII. 
Gracias a esta «Pensadora» se levanta un poco el velo sobre aquella sorda lucha entre el deseo de cambio que siente la mujer de la Ilustración y las fuerzas conservadoras, tradicionales e inmovilistas que ya desde entonces se oponían a toda mutación. Temeroso y vacilante, el varón español, critica con amargura el estado de la mujer española, pero, por otra parte, se aferra de una manera crispada y contradictoria a las reglas establecidas. Pensar es tan nefasto como trabajar; lo uno y lo otro amenazan el pudor y la virtud. Debe apartarse a las mujeres de empleos incompatibles con la modestia de su sexo:

y si el huso, la rueca y la aguja han sido siempre su heredad y patrimonio, yo creo que esto se ha establecido menos por acomodarse a la delicadeza de su constitución, que para no maltratar aquel pudor que debe ser alma de todas sus acciones...9

Si los deseos de Beatriz Cienfuegos son los de una minoría «ilustrada», éstos están totalmente segregados de la masa de mujeres españolas. Apenas si son comprendidos por las otras mujeres nobles y burguesas de las ciudades prósperas del país, aquellas que gastan las fortunas de sus maridos y a quienes repugna trabajar o ocuparse de tareas incompatibles con su virtud. Más sordas permanecen aún a su llamada las restantes mujeres, mayoría secularmente silenciosa y analfabeta por añadidura: unas están en el convento, otras trabajan la tierra manejando la azada o el arado, algunas hasta participan en la construcción de carreteras y finalmente las hay que engrosan las tropas de mendigos errantes por los caminos y pueblos. En este país esencialmente agrario, las mujeres son hábiles y fuertes como el hombre. Hijas del campo o manolas barriobajeras, ellas se lanzarán a la lucha contra el invasor napoleónico e intervendrán constantemente con el mismo coraje que los hombres, en la inacabable serie de motines y agitaciones que salpican el siglo xIx y la primera mitad del xx, desde el Motín de Aranjuez en 1808 hasta la Guerra Civil.

La Pensadora fue una anticipación original del feminismo español, a la vez que un feliz inicio de prensa femenina, pero no tuvo seguidores inmediatos. Carlos IV denegó la autorización de publicar en 1795 una revista, El Diario del Bello Sexo. Sólo en 1822 aparece El Periódico de las Damas, ${ }^{10}$ el primer semanario dedicado a las modas. Su principal redactor,

9. Nipho. Diario extranjero. Noticias importantes y gusosas. Madrid, 1763. Citado por Martín Gaite, op. cit., p. 220.

10. M. Tuñón de Lara, La España del siglo XIX (Barcelona: Laia, 1975), t. I, p. 87. 
León Amarita, editaba también El Censor y su iniciativa se concretó en una revista enteramente dedicada a las mujeres según el modelo de Ladies Journal y del Journal des Dames. Su contenido son las novedades de la moda francesa, algunos consejos de belleza e higiene, distracciones en prosa y verso y acertijos. Entre las suscriptoras se distribuían además algunos diseños de modas entresacadas de L'Observateur des Modes. Apenas duró seis meses y murió por falta de lectoras."

Estamos casi al final de un breve período liberal (1821-1823), durante el cual se tomaron algunas disposiciones públicas de importancia, como la enseñanza pública y gratuita. Por aquel entonces el porcentaje de analfabetos era particularmente elevado entre las mujeres. En 1820 se crea en Madrid una Escuela Lancasteriana femenina, que dirige una joven de 19 años, Ramona Aparicio. En ella se sigue un método de enseñanza colectivo, según el cual los más avanzados enseñan a los otros. La prensa no es accesible más que a una minoría de intelectuales, comerciantes ${ }^{12} \mathrm{e}$ industriales de ciudades como Cádiz, La Coruña, Santander, Bilbao, Valencia, Barcelona y Madrid, que van a intervenir de manera decisiva en el desarrollo económico e industrial del país. Ellas son el asiento de los movimientos liberales y también los centros en donde se publicaron las primeras revistas femeninas.

Y así entramos en la Década Ominosa. Madrid tenía 65 periódicos cuando Fernando VII juraba la Constitución; sólo le quedaban 5 en 1824, primer año de vuelta al Absolutismo. Toda la legislación liberal es derogada, la reforma universitaria anulada, se cierran Universidades en provincias, la enseñanza de las matemáticas y de la astronomía es sustituida por la de la música, la danza y la esgrima, y la vida nacional se petrifica por Real Orden. Las persecuciones y ejecuciones se ceban en los liberales. Mariana Pineda, acusada de «exaltada adhesión al sistema constitucional revolucionario», es condenada a muerte. Su crimen fue el haber bordado con sus propias manos una bandera republicana.

El silencio se cierne sobre la prensa y sobre todo otro tipo de actividad femenina. Aparte de El Correo de las Damas, que aparece en Madrid en 1833, y del que solamente sabemos que era una mala adaptación del Petit Courrier des Dames, de París, hay que esperar hasta los años 40

11. Eugenio Hartzembusch, Apuntes para un catálogo de periódicos desde 1661 a 1871 (Madrid: Sucesores de Rivadeneyra, 1904), p. 37.

12. María Lafitte, La mujer en España (Madrid: Aguilar, 1964), p. 151. 
para que pueda hablarse de un nacimiento de la prensa femenina. Éste se debe gracias a una mayor libertad de prensa, aun cuando los periódicos que nacen son casi todos literarios, económicos, artísticos y de modas.

En 1833, María Cristina es proclamada regente en sustitución de su hija Isabel II. Se abren los conflictos dinásticos al ser reconocido don Carlos como rey al mismo tiempo. Los liberales apoyan a la regente y el poder central inicia entonces un período de tolerancia. La economía también acusa aires de renovación a pesar de las Guerras Carlistas. Son los inicios de la Revolución Industrial en la península (el primer telar mecánico es inaugurado en 1833). Los liberales exiliados regresan, las Universidades abren de nuevo sus puertas y proliferan los periódicos. Las ideas democráticas y republicanas se difunden gracias a hojas como La Bandera, El Nuevo Vapor, El Huracán. En 1836 aparecen 36 nuevos periódicos en Madrid y entre ellos el primer periódico ilustrado. En 1840 hay 50 más. ${ }^{13}$ La población de Madrid es por entonces de medio millón de habitantes. En 1850 el número de periódicos que circulan por la capital es de 147.

Aparecen por doquier toda clase de revistas con títulos prometedores: La Psiquis, en Valencia; El Iris del Bello Sexo, en La Coruña; La Espigadera, La Mariposa, en Madrid. La mayor parte son revistas literarias que se hacen eco del movimiento romántico que invade España, y contienen al final media columna de modas y algún figurín. Una excepción bastante curiosa es: El Gobierno Representativo y Constitucional del Bello Sexo Español, que se publica mensualmente en 1841 y describe la Constitución de un «Gobierno femenino» en España, así como las sesiones de su Corte.

Pero la revista más notable es, sin duda, La Moda, de Cádiz, que aparece en 1841, creada por un periodista conservador de El Globo, F. Flores Arenas, y que seguirá publicándose hasta 1927. Revista de las familias gaditanas, alcanzó un éxito que rebasa la esfera local. Como ocurre con muchos periódicos y revistas gaditanas, no sólo se vende en toda Andalucía, como era costumbre entonces (Cádiz fue en lo referente al periodismo y la política una de las primeras ciudades españolas en gran parte del siglo xIx), sino que alcanza carácter nacional. En 1861 cambia su formato al de pliego mayor, aumenta sus páginas y adopta el nombre de La Moda Elegante Ilustrada, y en 1870 se publica en Madrid. Es, sin duda, la primera revista de modas seria que recluta el suficiente número de lectoras para remontar las crisis económicas y políticas de la época $y$, a la vez, nos ofrece una información interesante de la vida cotidiana

13. H. F. Schulz, The Spanish Press (Univ. of Ill., Chicago. Urbana, 1968), p. 66. 
de las mujeres de la alta sociedad a lo largo de todo este período. ${ }^{14}$ En ella colaboran María del Pilar Sinués y Robustiana Armiño de Cuestas, así como Gertrudis Gómez de Avellaneda. Esta última es aquella «Tula», poetisa y novelista, que en 1853 intenta entrar en la Academia Española de la Lengua y que no es aceptada por temor de que los atractivos físicos de una mujer provoquen en aquellos sesudos varones un estado de embelesamiento que enturbie sus mentes y los incapacite para enfrentarse con las reglas de la prosodia y de la sintaxis. ${ }^{15}$

El Defensor del Bello Sexo es otro periódico de literatura, moral, ciencias y modas, dedicado exclusivamente a las mujeres, en cuyo frontis campea todo un programa: Castidad, Pudor, Sensibilidad, Beneficencia. Su director, José de Souza, pretendía enseñar a las mujeres el «arte de pensar», ya que tanto influyen en las costumbres, y en la felicidad o infelicidad de los hombres. Pero con cuidado, dice, no se crea por esto que el bello sexo deba ser educado para las cátedras y las disensiones políticas: los extremos disgustan y no les es lícito invadir los dominios que por la naturaleza y las leyes nos están concedidos. ${ }^{16}$

Allí se publican, con todo, los poemas de Carolina Coronado, la «musa de conspiradores», una de las escasas poetisas románticas que va a luchar con brío por defender sus ideas. Educada sólo para bordar y estar confinada en su casa, estudiaba en contra de la voluntad de su madre y sufrió con particular intensidad su condición de mujer. En esta revista aparece su poema «A Luisita», en donde expresa su frustración:

\author{
Al cuerpo cuatro paredes \\ nos dan, porque viva en calma. \\ Mas ¿cómo pudiera el alma \\ fugarse de tal prisión? \\ En la ignorancia nos bunden, \\ sin pensamientos quedamos \\ $y$ asi presas nos ballamos \\ en alma y corazón. \\ Oprimidas, silenciosas, \\ afligidas, descontentas. \\ Si pasiones turbulentas
}

14. Ramón Solís, Historia del «Pensamiento Gaditano», 1800-1850 (Cádiz: Instituto de Estudios Gaditanos, 1971), p. 316.

15. María Lafiitte, op. cit.

16. El defensor del bello sexo, 2, septiembre 1845, p. 1 . 


\begin{abstract}
nos osan acometer, dámosles tierna acogida por tener en este encierro en cambio de tanto bierro la libertad de querer. ${ }^{17}$
\end{abstract}

Aquellas mujeres literatas de esta generación romántica tienen, es cierto, una vida sentimental muchas veces agitada y en cualquier caso más libre que la de sus congéneres; pero, nacidas en aquella clase burguesa que se consolida entre 1854 y 1869 , les es tremendamente difícil, más bien imposible, ir más allá del lamento lírico de sus escritos y de traducirlo en acción. Por nada de este mundo habrían soportado la reprobación de su clase y su tímido inconformismo será condenado al fracaso. La necesidad angustiosa de seguridad que experimenta la burguesía, el miedo a todo cambio, sirve de freno a la acción femenina.

Po: otra parte, la mujer se halla en una situación difícil: idealizada y a la vez despreciada por el hombre, quien le reprocha con amargura no ser aquella estatua perfecta e irreal que él ha fabricado en su imaginación:

Vuestros besos son mentira, mentira vuestra ternura. Es fealdad vuestra hermosura, vuestro gozo es padecer... ${ }^{18}$

Las delicias del amor-pasión de que tanto se habla, son para las otras. ¿Qué otras? La felicidad es precaria y peligrosa, sólo el amor maternal es admisible, amor hasta la exageración y a veces nocivo, pero el único que les es permitido cultivar sin pecar. Por otra parte, la virtud es como un título nobiliario o una buena fortuna, un capital que hay que proteger y más de una vez el único de que la mujer dispone para poder casarse.

$\mathrm{El}$ «sentar cabeza», constituir una familia con una mujer virtuosa es para el hombre una manera de consolidar su posición económica, social y política.

El lenguaje romántico de estas revistas se volverá exaltado y casi religioso cuando los discípulos de Cabet y Fourier tomen la defensa de la

17. El defensor del bello sexo, 4, noviembre 1845, p. 70 .

18. José Espronceda, Obras poéticas completas (Madrid: Aguilar, 1968). Citado por Federico Revilla en $\mathrm{El}$ sexo en la bistoria de España (Barcelona: Plaza y Janés, 1975), p. 233. 
mujer como «ser social». En efecto, vemos entonces surgir en la prensa una corriente de ideas fourieristas, feministas y también espiritistas. En 1846 se publica en Barcelona una revista de la que solamente sabemos que fue dirigida por Víctor Balaguer, que describía la condición de las mujeres como «una triple esclavitud frente a sus padres, su marido y sus hijos, y que solamente puede encontrar solución si se considera el problema en su totalidad». Se trata del Pensil del Bello Sexo. ${ }^{19}$

Al mismo tiempo, 1846, los discípulos de Cabet publican también en Barcelona una revista, La Madre de Familia, que está dirigida por Narciso Monturiol. Personaje curioso éste: Narciso Monturiol es un político, inventor del primer submarino, «El Ictineo». Afiliado al Partido Republicano, edita también La Fraternidad y El Padre de Familia, que fue denunciado por el fiscal de imprenta como "comunista», a consecuencia de lo cual tuvo que exiliarse en Francia. He aquí lo que dice a las madres de familia:

Si el funcionamiento actual de la sociedad doméstica es desafortunado, ello se debe al predominio de la idea de lucro como criterio para la formación del hogar, el cual sólo ofrece tres posibilidades a la mujer, todas ellas igualmente insatisfactorias, la de «señora», «esclava» o «prostituta». ${ }^{20}$

Joaquín Abreu, uno de los principales propagandistas del Fourierismo en España escribió varios artículos sobre la condición femenina en $\mathrm{El} \mathrm{Na}$ cional de Cádiz. La mujer — dice- goza de una ventaja sobre el proleta-

19. A. Elorza, «Feminismo y Socialismo», Tiempo de Historia, 3, 1974, p. 55. Por otra parte, encontramos en El Meteoro, 12, 1845, el artículo siguiente:

El Pensil del Bello Sexo.

Esta obra, debido al lozano ingenio de nuestras poetisas, es la primera que se publica en España. Barcelona, la ciudad que en esta época parece destinada a presentar y promover toda clase de innovaciones ha querido distinguirse en la parte literaria dando a luz a esta notable recopilación, que aunque diminuta, no dejará de producir algún día óptimos frutos. La aparición del Pensil merece citarse como novedad porque su objeto se cifra en abrir una nueva senda para el completo desarrollo e instrucción de la mujer. El pensamiento que en ella domina fue muy aplaudido y su digno director, el señor Balaguer, se ha arrojado a la arena clavando el estandarte bajo el cual se han de agrupar en adelante las mujeres que por sus talentos han de deslumbrar al mundo...

20. A. Elorza, El Fourierismo en España (Madrid: Ed. de la Revista del Trabajo, 1975), p. 55 . 
riado porque tiene los medios de transformar su condición y de demostrar a sus opresores el camino de la libertad. No se trata aquí, evidentemente, de la mujer proletaria. Cuando los condiscípulos de Abreu quisieron fundar un falansterio en Cádiz, cosa que les fue terminantemente prohibida por Espartero, lo habían concebido así:

La mujer aquí es libre, es independiente; tiene los medios de desarrollar y ejercitar todas sus tacultades materiales e intelectuales; y no debe a nadie más que a ella misma su subsistencia; ya no será carga del hombre sino su consuelo y su dicha ya que el matrimonio no es su único destino. ${ }^{21}$

Por aquel entonces se traduce un opúsculo de J. Czinsky, discípulo de Fourier, y cuyo título era «El porvenir de la mujer». Su prólogo, «Una palabra a las mujeres españolas dirigida por una compatricia», es una llamada a las mismas para que difundan la verdad, la idea del nuevo mundo social de Fourier:

Trabajad en vuestro círculo influyente, para que cuando la inteligencia de la joven reina Isabel II se halle bastante desartollada para juzgar la importancia de la idea que este ingenio nos presenta, la halle generalizada en los ánimos que la cercan y el deseo de la gloria y de imitar a la inmortal Isabel I la haga levantar un falansterio en España. ${ }^{2}$

El Pensil Gaditano es el órgano por el cual se expresaban los seguidores de Fourier. A partir de 1857 será dirigido, bajo el nombre de El Pensil de Iberia, por Margarita de Celis, M. José Zapata y José Bartorelo. Colaboran Pi y Margall y Fernando Garrido, el primer doctrinario de una tendencia socialista en España. M. José Zapata, que ya había publicado algunos poemas en la revista El Meteoro está muy influenciada por Fourier, sobre todo en lo que concierne a la condición femenina. El lenguaje empleado por ella, igual que el de Margarita Celis, es una mezcla extraña: a ratos místico (da la impresión de leerse a algún émulo de santa Teresa), a ratos plenamente realista. De hecho, ellas se sentían los apóstoles de una nueva religión: «Mas el día es llegado, no hay duda, en que brillen del sol nuevos albores...» $\mathrm{Y}$ este paraíso que anunciaban no podían des-

21. Ibid., p. 57.

22. Ibid., p. 167. 
cribirlo más que empleando el vocabulario cristiano y evangélico al que estaban habituadas. Fourier es el discípulo de Jesús:

\section{Que pudiera decir del bombre justo que de Jesús siguiendo las doctrinas derramó flores recogiendo espinas...}

$\mathrm{Y}$ las «Leyendas Morales» comienzan así: «En aquel tiempo decía Jesús...»

Debajo de este estilo surge por vez primera la idea de una conciencia de clase y de sexo. Son estas mujeres, al margen de su lenguaje y de la mediocridad de su poesía, las pioneras del feminismo libertario.

Por primera vez la relación hombre-mujer aparece formulada en términos de opresión, semejantes a los del Capitalismo-Proletariado. Estas relaciones no podrán cambiar sino a partir de una Revolución Total de la sociedad que deberá basarse en los principios de armonía y atracción pasional. La condición femenina es analizada en el ensayo «Injusticia social», de Margarita Pérez de Celis. Esta autora llama la atención sobre las desigualdades de salario existentes entre hombres y mujeres que trabajan en las mismas condiciones, citando y comparando cifras concretas. De donde concluye que pocas mujeres tienen la suficiente virtud para vivir del sudor de su frente y se ven obligadas a mendigar, o su miseria e ignorancia les impulsan a la prostitución y, en el mejor de los casos, al matrimonio interesado. Una vez allí, a cargo del hombre, sufre de la dominación de quieñ da y de la dependencia de quien recibe; el círculo infernal comienza: ninguna acción común y en pie de igualdad puede resultar así, ni en la familia ni en la sociedad.

El Pensil de Iberia termina con la intervención del obispo de Cádiz, quien obtiene del gobernador de la ciudad su prohibición. Según la Real Orden del 15 de julio de 1850 , «todas las publicaciones que contengan doctrinas dirigidas a relajar los lazos sociales, atacar la propiedad, a vulnerar la religión del Estado o a ofender las buenas costumbres» debían ser prohibidas. El obispo de Cádiz, encargado de la censura, encuentra en $E l$ Pensil de Iberia «casi todos los errores contrarios a la Fe y la Moral Cristiana, muy especialmente en los artículos que encabeza con el epígrafe "Leyendas morales", en los que se llega al extremo de suponer que Nuestro Señor excita con su Sagrada Humanidad el amor impuro, condena el estado de su matrimonio y santifica el crimen del adulterio... La tendencia general de todos los artículos contenidos en los seis números de dicho periódico es proclamar la emancipación y regeneración de la Humanidad por los principios socialistas. Hecho que no sólo afecta la conciencia cris- 
tiana, sino que pone en alarma a todo hombre pensador, porque semejantes escritos llevan en sí los principios disolventes de la autoridad, del orden, de la justicia, de la disciplina doméstica y de cuantos elementos son necesarios para el buen régimen y organización de la sociedad. ${ }^{23}$ El último número de El Pensil es de agosto de 1859. Habrá que esperar a 1866 para ver aparecer La Buena Nueva, «periódico de literatura, ciencias y artes e industrias», dirigido por el mismo grupo, es decir, M. José Zapata, Margarita Pérez de Celis y J. Bartorelo. Esta nueva revista apenas habla ya de espiritismo y no participan en ella colaboradores conocidos, excepto José Mañé y Flaquer. El tema principal es el femenino y la difusión del fourierismo. En ella se insertan fragmentos traducidos libremente del Monde Industriel et Societaire. El lenguaje sigue impregnado del vocabulario y simbolismo cristianos. María aparece mezclada con la emancipación de la mujer; ella es la compañera del hombre de la armonía, Jesús, liberador de las naciones, mientras que José, el artesano, es el ejemplo del proletariado.

Estas rebeldes estaban animadas por un auténtico fervor religioso que propaga «a través de estas páginas», pero su audiencia debió ser escasa. Sería sumamente interesante conocer la historia personal de aquellas mujeres, su itinerario, pero por desgracia apenas sabemos nada. ${ }^{24}$ No por eso dejamos de admirar la modernidad de sus aspiraciones.

El artículo que abre la revista, «Misión de la pareja humana sobre la tierra», denuncia la explotación de la mujer, privada de todos sus derechos y a quien son negados todos los puestos y cargos públicos. Intelectualmente incapacitada, queda confinada en los trabajos caseros o en los empleos más ínfimos. Por otra parte, nota el autor J. Bartorelo, el español es, de toda Europa, el menos indulgente con la mujer y el más retrógrado

23. A. Elorza, «Feminismo y Socialismo», art. cit., p. 60.

24. Leemos en La Violeta, en 49, 1863, el artículo siguiente:

Suscripción a favor de la desgraciada y apreciable poetisa gaditana doña M. Josefa Zapata.

... empezó sus trabajos literarios en 1846, en El Meteoro, que se publicaba en Cádiz, los cuales fueron reproducidos por los periódicos de la capital, así como por otros de Barcelona y Granada. Fundadora y colaboradora de El Pensil Gaditano y de Iberia, tuvo que dedicarse desde joven al trabajo manual de labores de primor para atender a su subsistencia, como a la de sus ancianos padres, sacrificando así más de una vez en aras del deber filial su porvenir y su fortuna; privada de la vista ha más de un año, efecto de su excesivo trabajo, se sostiene únicamente por los caritativos auxilios de algunas personas y con el apoyo que le prodiga otra señora amiga suya, colaboradora también del Pensil... 
en lo que toca a la «eterna ley del progreso» porque sus Gobiernos, de todos los matices, incluso el Progresista, no le han dejado evolucionar ni disfrutar de otra cosa que de una «fementida libertad». ${ }^{25}$

Acusado de ser el propagador de teorías espiritistas y de difundir el pensamiento de Fourier, «el más terrible y atrevido socialista», para quien «nada de lo que existe está en su lugar» y para quien la sociedad no es otra cosa que un enorme teatro «en donde no reinan más que la opresión, el dolor y el sufrimiento», el periódico de M. José Zapata es clausurado en 1866 , cuando ya estaba amenazado de ruina.

Pero volvamos atrás, al Madrid de los años 50 , donde se desencadenaba una tormenta en torno a la desigualdad de sexos y contra ella. La revista Ellas, Órgano Oficial del Sexo Femenino, cuya directora era Alicia Pérez de Gascuna, y donde colaboraban Ángela Giani y Carolina Coronado, declaraba:

Nosotras, amazonas del siglo xIx, aspiramos a llevar la revolución adelante en pro de nuestras ideas, para ello contamos con nuestro sexo, que en masa nos ayudará con su lengua y su pluma.

Esta profesión de fe feminista recogía los ecos de una disputa que tuvo lugar en aquella época entre dos periódicos satíricos. Uno de ellos era El Sueco, periódico demócrata que se burlaba de las reivindicaciones de la mujer en Francia, particularmente con motivo del discurso del diputado Schoeller en la Asamblea Nacional del país vecino recabando el derecho de petición para la mujer. Su oponente, El Toboso, dirigido por Sixto Cámara, un joven fourierista, incitaba a las mujeres españolas a pronunciarse en política. Aparece allí un personaje ficticio, Robustiana Covarrubias, que reclama la representación nacional para la mujer, el derecho de petición, su emancipación con respecto al hombre y la igualdad jurídica. El redactor de El Sueco responderá que la emancipación de la mujer era la última calamidad que faltaba... ${ }^{26}$

La proclama de Ellas provoca en el periódico progresista Novedades el comentario siguiente:

Más ganaréis, escritorcillas, en sellar vuestra boca y no pronunciar ridiculeces tantas: dedicaos al huso y a la rueca, al esco-

25. A. Elorza, El Fourierismo en España, op. cit., p. 52.

26. A. Elorza, «Socialismo y Feminismo», art. cit., p. 52. 
beo y al fregado, al cosido y al planchado, y no profanar con vuestras quimeras el santuario de las leyes y la recta vara de la justicia. ${ }^{27}$

El periodista en cuestión prodiga a las redactoras y a las mujeres en general los epítetos de fatuas, cabezas de chorlito, tontitas, fanfarronas, y otras lindezas por el estilo, y añade: «...y lo digo sin orgullo, nos merecemos la superioridad sobre vosotras.» ${ }^{28}$

Desanimadas, sin duda, las redactoras, Ellas perdió poco a poco su virulencia y se convirtió en una revista literaria y de modas como tantas otras. El subtítulo que ostentaba al principio, «Órgano Oficial del Sexo Femenino», se transforma en el mismo año, en «Gaceta del Bello Sexo». En 1852 nueva metamorfosis, esta vez de nombre, y se llamará en adelante Correo de la Moda y Álbum de Señoritas, que acaba siendo una imitación de las revistas francesas de moda, en particular de Le Courrier de la Mode.

Su presentación a los suscriptores de la segunda época es una verdadera capitulación: todo lo que habían querido decir en la fase precedente había sido mal interpretado, ellas comprenden muy bien sus sagrados deberes en la sociedad, la verdadera misión de la mujer está en el hogar y su gloria es reinar allí con ternura, modestia y espíritu cultivado, y «de ninguna manera - dicen- apeteceríamos esa completa emancipación de nuestro sexo..." ${ }^{29}$ Este episodio arroja alguna luz en esa dinámica social y política del país dividido entre las fuerzas más tradicionales (los santones), los que se dicen progresistas, pero siguen anclados en el statu quo, y los liberales que impulsan hacia la renovación. $\mathrm{La}$ prensa femenina, para sobrevivir, a duras penas, debía adaptarse a ese contexto social. La mujer de la alta sociedad, la única que podía permitirse el lujo de escribir, no podía dar libre expresión a su afán de renovación. Fue incapaz de romper los moldes impuestos por una religión que la encerraba en su rol de madre y una sociedad que la quería subordinada y sumisa; estaba condenada, salvo excepciones verdaderamente geniales, a una existencia de rutina, de resignación fatalista o de intrigas.

El Correo de la Moda y Album de Señoritas, «periódico del Bello Sexo», es un semanario dirigido hasta 1874 por J. J. de la Peña. También se propone en su prospecto educar a la mujer.

27. Ibid., p. 52.

28. Ellas, 1, septiembre 1851, p. 8.

29. Ellas, 1, septiembre 1851, p. 2. 
Todas las clases de la sociedad - dice-, en que el hombre ejerce sus facultades intelectuales, buscan en la prensa los elementos de su desarrollo. Es tiempo de ocuparse de la mujer y nosotros vamos a emprender la delicada tarea de publicar un periódico que reúna las cualidades de religioso y moral, las de instrucción y recreo, un periódico que desde el perfumado gabinete de la elegante pueda trasladarse al reducido aposento de la colegiala y de aquí al taller de la graciosa modista, y en el cual, la elegante, la colegiada y la modista tengan un objeto que alimente su curiosidad y robustezca su educación. ${ }^{30}$

Contiene también artículos sobre la vida social y artística, ensayos y novelas. Éstas, curiosamente, suf:en censura. Primero, una de las suscriptoras se inquieta de que en las novelitas se mezclan algunos acontecimientos o palabras «impropias o de poca moralidad». Dos meses más tarde, la redacción anuncia que en cumplimiento de las últimas disposiciones del Gobierno, suspenden la publicación de novelitas, y mientras someten algunas a la censura, tendrán que publicar unos interesantes estudios geográficos. ${ }^{31}$

En 1874, toma la dirección. Ángela Grassi, quien con otras escritoras como Juana de Balmaseda, colaboran en la redacción. Es entonces, una revista muy ilustrada, con muchas modas y poca literatura.

Otra revista literaria de aquel tiempo es La Mujer, «Periódico Defensor y Sostenedor de los Intereses del Sexo». La publica una sociedad de mujeres escritoras que evitan cuidadosamente el tema de la moda. Sus redactoras tienen algunas reivindicaciones distintas. Declaran que su fin principal no es el mero capricho, ni darse a conocer como escritoras, sino el ser útiles a su sexo. Reclaman, por ejemplo, posibilidades de trabajo que les asegure la subsistencia y que no sea circunscrito a labores femeninas como el bordar y zurcir. Añaden que «... a pesar de todos los esfuerzos colectivos y constantes de los hombres, cesará toda limitación el día en que nuestro sexo se desprenda de su perjudicial timidez y sumisión, y con ánimo decidido se dedique a todas las labores que pueda desempeñar, atendidas sus particulares circunstancias».

Según ellas, la mujer tiene que emanciparse de la tiranía de los especuladores que con sus desvelos se enriquecen. Se preocupan también de la prostitución y quisieran encontrar medios para impedir que

30. El Correo de la Moda, 1 , noviembre 1851, p. 1.

31. El Correo de la Moda, 10, marzo 1851, y 13, mayo 1851. 
las seducciones de los hombres, auxiliados por la miseria de las víctimas y la corrupción de las costumbres de la época, arrastren diariamente a miles de mujeres al vicio. Pero esta revista es tan efímera como las anteriores, ya que dura apenas un año.

Pero en vano buscaremos información acerca de las condiciones generales de la vida de la mujer española (salvo la burguesía), en esta primera mitad del siglo xix, en la prensa de salón, ni en los historiadores. Tampoco existen estadísticas que nos den alguna idea de los problemas de trabajo o de instrucción. Sabemos poco del papel que juegan en la naciente industrialización que caracteriza esos años. ¿Cuál es la situación de la mujer rural en un momento en que un tercio de la población activa del país, y lo veremos más adelante, está constituida por los campesinos? ${ }^{32}$ Por alusión conocemos algo, por ejemplo, de esos miles de muchachas procedentes del campo que vienen a la ciudad como criadas; otras, madres sin marido a quienes arrebatan sus hijos (o que se desprenden de ellos), son exhibidas en la plaza pública como amas de cría, su leche es catada, discutido su precio, no con ellas, sino con quien las ha conducido allí, como si fueran ganado. ${ }^{33}$ ¿Qué hay acerca de las prostitutas de Madrid, que proliferan en el barrio de las Huertas, cerca del Hospital de San Juan de Dios, especializado en enfermedades venéreas, y que más de una vez se amotinaron? ¿Qué es de ellas cuando se las recluye en ciertos conventos que se dedican a la salvación de «aquellas almas»? ¿Quiénes son las religiosas encargadas de educarlas y rehabilitarlas? ¿Cómo viven aquellos millares de mujeres que se dedican a las faenas más ínfimas en los hospitales, asilos y prisiones, mientras que los sacerdotes y monjes se dedican más bien a la enseñanza o a la «reconquista espiritual» de la burguesía y de las clases dirigentes?

Pero todo esto rebasa ampliamente el marco de nuestro trabajo. Nosotros nos limitaremos a ver lo que dice la prensa femenina. Con frecuencia, sus páginas exhalan un aroma de aburrimiento y melancolía; es el ambiente de aquellas damas acantonadas en un universo de bordados y labores, de faenas caseras y de menudos detalles familiares. Separadas del mundo exterior por lujosas y espesas cortinas, su vida apenas llegará a una mayor madurez que la de los hijos que tan prolíficamente traen al

32. «... el $70 \%$ del personal en las faenas agrícolas, como la recolección de la aceituna, eran mujeres y niños, trabajando a destajo y ganaban apenas dos reales por día. En 1867 de los 6.764 .000 españoles activos, 5.000.000 trabajaban en la agricultura.» M. Tuñón de Lara, La España del siglo XIX (Barcelona: Laia, 1975), t. I, p. 198.

33. María Lafitte, op. cit., p. 148. 
mundo. ${ }^{34}$ Percibimos igualmente la frustración y la amargura de aquellas mujeres que no pueden llegar a aquel ideal de maternidad que la sociedad les propone; es el drama de la mujer sola, de la solterona, la fea, la que lleva una existencia parasitaria, sin casa propia y sin servir para nada.

Incluso de la moda sabemos muy poco. ¿Quién la sigue, de hecho? ¿Las actrices, las señoras de alto copete, las clases medias de la Villa y la Corte, siempre prestas a imitar a la nobleza (quien a su vez reproduce los modelos de París)? En todo caso Madrid es un punto singular, mientras el resto del país persiste en sus costumbres ancestrales vinculadas a la región, al hábitat, a la edad y a la condición social. La mujer casada se distingue de la viuda, como la prostituta de la honrada, en su vestir.

\section{$* \quad *$}

En la segunda mitad del siglo xIx, observamos un incremento notable de la producción periodística que se acentúa aún más durante la Revolución de Septiembre. Trescientas nuevas publicaciones ven la luz en el transcurso de los veintisiete meses que separan el Gobierno Provisional de la Coronación de Amadeo de Saboya (1868-1870).

Como de costumbre, predominan los satíricos y los literarios. Esta explosión periodística no está en consonancia con la audiencia, y muchas de ellas tienen una existencia efímera. En 1860 solamente uno de cada cuatro españoles sabía leer, y en algunas provincias el analfabetismo sobrepasaba el $80 \%$. En 1870 sólo el 9,6 \% de las mujeres sabían leer y escribir, pero no obstante, la prensa femenina se halla entonces en su apogeo y gran número de mujeres se consagran a la literatura. La mayor parte de toda esta producción proviene de Madrid, donde radican las clases sociales a quienes puede interesar este tipo de publicaciones: la aristocracia, los funcionarios, los políticos y la burguesía instruida. Pero también otras ciudades, particularmente Barcelona, Valencia y Cádiz, se ven presa de esa fiebre de publicaciones.

Por vez primera, en 1870 se otorga el permiso a los protestantes y librepensadores para publicar sus revistas. En marzo de 1873 aparece Los Descamisados, con un artículo de fondo titulado «Amor libre», que firma una «ciudadana Guillermina». Estamos en plena Primera República... Después de la revolución, las revistas de modas acusaban un cierto cambio de costumbres: los pantalones que llevaba George Sand y que

34. «La población es de 11.000 .000 en $1808,15.000 .000$ en 1857.» P. Vilar, Historia de España (París: Librería Española, 1963), p. 90. 
30 años antes habían escandalizado a los mallorquines, son ahora exhibidos con aire provocativo por una cierta actriz que posa, cigarrillo en mano... ${ }^{35}$

Durante el último tercio de siglo aparecen además una veintena de revistas, generalmente importantes y serias, publicadas por mujeres y para mujeres. Junto a la nueva generación de políticos e intelectuales que han vivido los últimos años del reinado de Isabel II, y que anhelan, como los primeros románticos, una transformación del país, un grupo de mujeres de la burguesía madrileña y catalana se lanza ardientemente a la lucha. La única vía que les estaba abierta era el periodismo, y en sus publicaciones dejaron bien patente su temple y su talento.

De entre todas ellas, sobresale Concepción Arenal, fundadora de una revista llamada La Voz de la Caridad, que durante 14 años salió a la luz dos veces al mes y cuyo tema principal fue la reforma penitenciaria en España. Redactado y administrado gratuitamente, el producto de sus suscripciones era destinado a las familias pobres. Allí se denunciaton sin contemplaciones, y lejos de todo partidismo político, las graves deficiencias del sistema penitenciario del país. Concepción Arenal había nacido en El Ferrol en 1820. Disfrazada de hombre entró a los 21 años en la Universidad de Madrid y obtuvo su licencia en Derecho. Se casó en seguida con un compañero de estudios y comenzó a escribir artículos para la revista Iberia, firmando con el nombre de su marido. Quedó viuda muy joven, con dos tijos y sin apenas recursos para vivir. Entonces escribió un ensayo intitulado La Beneficencia, la Filantropía y la Caridad, que remitió a la Academia de Ciencias Morales y Políticas firmando con el nombre de su hijo, que a la sazón tenía 10 años. Muy pronto fue nombrada visitadora de las prisiones de mujeres en Galicia, puesto que fue creado para ella. En el ejercicio de sus funciones interrogó a más de 400 presas y transcribió para su Gobierno todas aquellas entrevistas. Fruto de este trabajo es su libro Cartas a las delincuentes. Mientras su amiga la Condesa de Mina leía estas cartas a las presas, ella anotaba cuidadosamente sus reacciones y preparaba los informes solicitando las reformas que aquéllas reclamaban. Creó en Madrid un Centro de Mujeres para la Acción Social, y un Servicio de Sanidad Militar. Escribió muchas páginas sobre el trabajo de la mujer, sobre los delitos colectivos y sobre las funciones del visitador de prisiones. Ella fue la primera criminalista y la primera autora de un tratado de Derecho Internacional en España. Los títulos de sus libros, La mujer de porvenir, La emancipación de la mujer en España, La Educación de la mujer en España, El tra-

35. F. Soldevila, Historia de España (Barcelona: Ariel, t. 7), p. 121. 
bajo de las mujeres, La mujer en su casa, dicen mucho de sus preocupaciones. Estos libros, junto con sus artículos, constituyen documentos históricos inestimables en torno a la condición de la mujer en nuestro país.

Otras revistas, como La Instrucción de la mujer, Ecos de Auseva, La mujer cristiana, etcétera, se preocupan más bien de la educación de la mujer y de sus actividades de beneficencia. La influencia de Concepción Arenal es en ellas bien patente. Su espíritu liberal y tolerante, su preocupación social y pedagógica, se avenían muy bien con los ideales de un grupo de gente que pensaban que la salvación del país estaba en organizar un programa educativo que arrancaría al pueblo de su retraso intelectual. Estuvo ligada por una gran amistad con Francisco Giner de los Ríos, fundador de la Institución Libre de Enseñanza, una de cuyas aspiraciones era la educación de la mujer. Ya algunos años antes, Fernández de Castro había tenido la iniciativa de crear centros dedicados a la formación profesional de la mujer, como una Escuela de Maestras y la Asociación de Profesoras para la Enseñanza de la Mujer, la cual, según Concepción Saiz de Otero, sería la «célula germinal de la cultura femenina que se desarrolló en España durante el último cuarto de siglo».

$\mathrm{Si}$ bien es cierto que la Revolución de 1868 trajo también alguna ley favorable a la mujer, como la que concedía la patria potestad a la viuda, para las que quieren escribir, si son casadas, el artículo $5 .^{\circ}$ de la Ley del Matrimonio Civil ordena no publicar textos ni obras científicas o literarias, de las cuales son autoras o traductoras, sin tener licencia del marido, o en su defecto, autorización judicial competente. $\mathrm{Si}$ la mujer quiere ir a la Universidad será sólo con la autorización del Rector, y si el Catedrático se hace responsable del orden de la clase.

En este estado de cosas aparece en Madrid, en 1871 La Mujer, «Revista de Instrucción General para el Bello Sexo». Su primer editorial acusa el talento de las mujeres que en ella participan:

Muchas son las publicaciones que nacen y mueren cada día como lánguidas flores agostadas por el huracán, muchas las que sobreviven y se alzan vigorosas sobre las tempestades sociales, defendiendo doctrinas diversas, agrupaciones y personalidades; pero ninguna se ha encaminado única y exclusivamente a la mujer. La nuestra aparece con esa misión en el estadio de la prensa. Mujer, esposa y madre, antes que escritora, la fundadora de esta revista ha consagrado siempre sus tareas a enaltecer a su sexo, ha luchado con todas sus fuerzas en tan espinoso terreno reclamando el puesto que nos corresponde en la esfera social y enseñando a sus hermanas que su misión de caridad, de paz y de amor no 
está en las ardientes luchas de la política, terreno peligroso del sexo fuerte, sino en el fondo del hogar... Muchos siglos de subyugación moral han hecho de la mujer española un ser sin voluntad propia y sin iniciativa; la revolución puede cambiar nuestra condición social, si hay hombres que comprendiendo la importancia de la mujer, nos ayudan a perfeccionarla, y nos marcan los deberes y los derechos que nos son propios, guiándonos por el camino de la ilustración, a la luminosa esfera de la inteligencia y del saber, dejándonos tomar la parte que nos corresponde en las graves cuestiones sociales que deben resolverse y a que tanto se presta nuestra propia debilidad y nuestra natural ternura... No debe la mujer permanecer más tiempo en los niveles de la ignorancia; esto acarrea funestos males a la causa del progreso, porque se convierte en arma de partido, se explota su conciencia para fines reaccionarios y se introduce en la familia la semilla de la discordia, cuando todo en ella debe ser armonía y amor.

Por encima de la grandilocuencia de estilo, se adivina ya una toma de conciencia de una situación nueva, una ruptura que apenas se esboza, y cuyo alcance queda diluido bajo un cúmulo de seguridades y garantías.

Esta revista de ocho páginas contiene novelas, retratos de celebridades y ensayos sobre educación y ciencias. Hecho interesante es el que allí se publique una carta aparecida en la Revista Social de Madrid, firmada por una obrera de Málaga y dedicada a sus compañeras de trabajo:

A las trabajadoras malagueñas, y en su Semanario Particular a las carreteras, camilleras, torneras urdidoras, tejedoras y demás manufactureras...

Compañeras, el estado en que nos ha colocado el estúpido orgullo del hombre, que valido de la fuerza bruta ha considerado ser superior a nosotras, como si pudiera prescindir de la mitad del género humano, es bastante triste... (...) nos obliga a trabajar en fábricas, y donde nuestros burgueses se creen con el derecho a ultrajarnos, pisoteando la moral y la justicia, después de no tener más derechos como ser humano que los que ellos quieren dar, pues estamos obligadas por las circunstancias a sucumbir a sus despóticas costumbres, a la bárbara explotación y a la insalubridad de la fábrica... los obretos colectivistas, nuestros hermanos en la desgracia, los que en medio de una organización monstruosa levantan la bandera de la justicia proclamando los derechos de la mujer como ser complementario del hombre, nos 
llaman a su organización. Acudamos pues, que es remedio para cortar el mal, no permanezcamos por más tiempo en la ignorancia y en la indiferencia. Unámonos a todos nuestros compañeros revolucionarios y hagamos algo en bien del progreso. ${ }^{36}$

Otras revistas de Barcelona como El Partenon, y Asta Regia, dirigidas por Josefa Pujol de Collado y C. Soto respectivamente, ambas poetisas de la Renaixença Catalana, aparecen etiquetadas como revistas de literatura, ciencias. y artes, y no hacen prácticamente alusión alguna a las modas. Algunos anuncios, la crónica teatral y social, poesías y sobre todo ensayos, constituyen su contenido. Un artículo hace la apología de Safo y la compara con las mujeres más destacadas de ese momento, tan injustamente tratadas como ella. Hay también un alegato en defensa de la mujer adúltera. Otros temas hasta aquel entonces velados, se insinúan discretamente pero, en general, todo queda en buenos sentimientos.

En Barcelona también se publica en 1882 La Mujer, revista de dos páginas dirigida por una tal Mme. Aramburu y que no dura más que pocos meses, pasándose a convertir en El Álbum del Bello Sexo, órgano de la emancipación de la mujer, de corte científico y literario, que habiendo a su vez quedado sin respaldo económico por defección de unos accionistas, desaparece; pero sus redactoras fundan un poco más tarde, en 1883, La Ilustración de la Mujer. Ésta sobrevive hasta 1887 y está dirigida por Gertrudis Gómez de Avellaneda, Josefa Pujol de Collado y Dolores Monserdá de Maciá. Se proclaman instrumento de redención social de la mujer y por primera vez se observa una seria intención de organizar un movimiento y de expandirlo a través de toda la geografía española. Allí se hace mención de las asociaciones que van surgiendo en diversas capitales de provincia y del primer Congreso Femenino, que se organizó en Palma de Mallorca. Es asimismo el órgano del Congreso Nacional Pedagógico, de donde arranca el movimiento cultural que transforma la enseñanza primaria en España. A él asistieron 400 mujeres. En esta revista aparecen los nombres de las estudiantes universitarias que han terminado sus carreras. Allí se habla de los problemas de la formación de maestras de escuela, de la instrucción femenina, de la prostitución y de la situación de la mujer obrera. Se piden reformas legislativas en favor de la mujer. El tono es cada vez menos tímido; ya no hay tanto lirismo, sino exposición de hechos concretos que justifican la lucha que se ha emprendido. Un nuevo vocabulario hace su aparición: derecho, defensa de nuestros derechos, lucha por

36. M. A. Capmany, El feminismo ibérico (Barcelona: Ed. Oikos Tau, 1970), p. 137. 
nuestros derechos..., en sustitución de aquel otro que esgrimía los términos de: sacrificio, abnegación, modestia, virtud... Aquí leemos: «El hogar es un centro de abnegación y un núcleo de egoísmo», o bien: "La mujer no tiene más estofado que el matrimonio», "La mujer perfecta es corruptora y dañina. Mirándolo todo bajo el prisma de ese egoísmo sublime para el hogar, pero dañino para la sociedad, impide con todos los resortes de su influencia que sus hijos y su esposo se abstengan de hacer efectivos con actos, el alto sentido social que en muchos de ellos se ve.»

La influencia de Concepción Arenal sigue haciéndose sentir. ¿Será ésta lo suficientemente fuerte como para luchar contra la mentalidad general, contra este triste maridaje entre «ignorancia, religión y moralidad» que reinaba aún en el espíritu de la gente? Porque enseñar a leer a las mujeres era abrirles la puerta al vicio; ellas sólo tenían necesidad de servir a Dios, cuidar su casa y obedecer a su marido. Tales eran las conclusiones de una encuesta realizada por la Institución Libre de Enseñanza, sobre las causas del analfabetismo, y publicadas en su boletín. Eran, quizá, reminiscencias de la vieja querella entre la Iglesia y los Liberales, que comienza cuando las Cortes de Cádiz votaron en 1809 la supresión de los conventos y que culmina en la Desamortización de Mendizábal (1835). La Iglesia y los católicos no perdonarán jamás esta derrota al Liberalismo, al que calificarán del «último y supremo grado de perversión», y estigmatizarán la emancipación de la mujer durante la Revolución Francesa, como la causa de las más horribles licencias. La revista de la Compañía de Jesús se opone a que ahora sea extendida la instrucción a todas las clases sociales sin distinción de sexo. Se discute aún sobre la dimensión del cerebro de las mujeres y sobre su inferioridad física. Eran tan difíciles de convencer las mujeres como los hombres de las ventajas de la educación y de la acción social; sobre todo intento de esta índole campeaba el temor de perder su famosa «feminidad», de hacer peligrar la superioridad masculina; y en política, según el historiador F. Soldevila, las mujeres fueron en gran mayoría partidarias de la Restauración Borbónica, por todo lo que significaba de retorno a los principios tradicionales.

A fines del siglo xIx, la prensa femenina pasa por una serie de cambios significativos. Es ésta una fase crucial de su historia. Hace su aparición un nuevo lenguaje que no cesará de evolucionar hasta 1939, un lenguaje mucho más consciente y más sensible a todos los acontecimientos políticos y sociales que jalonan esta época. Cada vez se perfila mejor el conflicto entre el peso de la tradición y un profundo deseo de renovación y de libe- 
ración. Entre las actitudes de la burguesía y de la clase obrera se ve claramente un abismo. Vemos, por otra parte, aparecer nuevas imágenes de la mujer: la mujer de la pequeña burguesía, la hija del empleado, del comerciante o del militar, la mujer proletaria; y es precisamente la prensa femenina quien nos las pinta, a veces con los más vivos colores, sin pretenderlo explícitamente.

Estudiaremos más particularmente esta época en Cataluña, donde por razón de residencia tenemos a nuestra disposición la prensa local. La aparición de las revistas femeninas refleja perfectamente las fuerzas que polarizan la vida política y social del Principado; dos corrientes paralelas: el Movimiento Obrero y el Regionalismo. Barcelona desde comienzos del siglo xix era un centro de acumulación de capital de los repatriados de América, que sirvió como inversión en el comercio y en la industria. En 1832 se instala el primer telar mecánico y en 1833 nace la fábrica El Vapor, dándose cita tres elementos importantes del moderno mundo de la Industria: los telares, la metalurgia y el vapor. Las 337 fábricas que figuraban en un censo de por entonces tenían casi sin excepción los mismos nombres de la moderna burguesía industrial catalana. Igualmente se desarrolla la fabricación del cuero, papel, corcho y otros. La contribución det trabajo femenino fue fundamental en todo este proceso de industrialización español, y en particular, catalán. Hay en España, ${ }^{37}$ en 1857, 247.867 obreros en la industria y en las minas, de los cuales 45.754 son mujeres. Éstas trabajan en los textiles, la confección, pero también en las minas y en el metal. Había 300 mujeres en la fábrica de armas de Toledo, y en la industria del tabaco trabajaban casi exclusivamente mujeres. El salario en aquel entonces oscilaba entre los dos y tres reales por día (el kilo de pan costaba entonces de 0,35 a 0,50 ptas. según el lugar). Mientras que el de los hombres oscilaba entre 2,25 y 2,33 ptas. diarias. En Cataluña la situación no era mejor, y de los 54.273 obreros, 22.049 son mujeres. Las mujeres y los niños eran relegados a los peores puestos de trabajo y sus horarios eran de 10,11 y 12 horas de trabajo al día, en talleres mal ventilados e infectos. Muchas de aquellas mujeres dormían sobre balas de algodón. Otras, emigradas del campo, se alojaban en inmundas casas de huéspedes o en barracas donde se hacinaban varias familias.

Las proteínas de su alimentación provenían, en el mejor de los casos, de los arenques y del bacalao seco y salado que comían acompañado de garbanzos. Una anemia crónica, una fragilidad constitucional deplorable, condenaban a la clase obrera a ser presa de toda clase de enfermedades infecciosas como la tuberculosis (hereditaria), el tifus y el cólera.

37. M. Tunón de Lara, op. cit.. p. 247. 
Por otro lado, la falta de alojamiento, las condiciones de vida tan miserables empujaban al hombre a las tabernas, donde se gastaba frecuentemente el sueldo íntegro. Alli se le encontraba para contratarlo y hasta incluso para pagarlo. Muchas veces la taberna era propiedad del fabricante.

La prostitución era una plaga nacional. Estaba autorizada por el Estado y pagaba contribuciones, con lo cual se evitaba el escándalo. Pero a menudo la prostituta también procedía de familias de la clase media con dificultades económicas. La entretenida, «la amiga», era otra institución.

La burguesía deserta poco a poco de su posición liberal: apenas se consolidan sus posiciones olvida toda intención de lucha revolucionaria. Propietaria de grandes extensiones rurales, de la riqueza minera, de la industria, se enfrenta con un campesinado hambriento y un proletariado que vive en condiciones infrahumanas. Con una dureza extraordinaria se opone a los movimientos de asociación y se resiste a mejorar las condiciones de vida de los trabajadores.

Entre los años 1830-1860 surgen la primeras asociaciones obreras y hay momentos de agitación que culminan en sucesos como el incendio de la fábrica Bonaplata y la huelga general de 1855. Los obreros reclaman el derecho de asociación, lo cual provoca en el Album de las Familias, suplemento familiar del Diario de Barcelona, artículos como éste:

La obrera ha sido objeto de especial predilección por el clero y personas católicas de Alemania, puesto que desde el primer momento comprendieron que la mujer es, en la sociedad, un elemento esencialmente conservador, y que el día en que dejara de serlo, rodaríamos todos con rapidez vertiginosa hacia la disolución y la anarquía... El desarrollo de la gran industria le ha puesto en el trance de tener que optar entre los deberes de la maternidad o los de operarias de taller... Se ha procurado, con una imprevisión, que la diferencia de sexos se borrara lo más posible en la clasificación del trabajo, pero no advirtió que lo que ganaba el bolsillo con la nueva organización del trabajo, perdíalo la mujer como madre y como esposa, ya que la frecuentación de los grandes talleres, aparte de que le hace olvidar casi por completo sus quehaceres domésticos, la expone a mil peligrosas seducciones...

... Gracias a la influencia de las nobles y caritativas instituciones católicas alemanas, la obrera conserva su pureza, su caridad y su devoción, y adquiere el conocimiento debido para organizar un hogar, honrando al esposo y a todos los miembros de la familia. En esas familias reinará el orden, la economía y el espíritu de ahorro, y siendo felices, lo será también el marido, de quien 
podrá ya asegurarse que las antisociales no le contarán entre sus adeptos, dado que afluyen a sus filas los desesperados del mundo y aquellos obreros que están a disgusto en su casa y van a la taberna en demanda de solaz y esparcimiento que no encontrarán en aquélla.

El artículo es asimismo un eco de la toma de posición de la Iglesia, en el Concordato de 1850 , frente a los problemas obreros. ${ }^{38}$

Los movimientos revolucionarios y de asociación tuvieron principios difíciles, pero el éxito de la Asociación Internacional de Trabajadores, con su órgano «La Federación», fue enorme.

Entre Andalucía y Cataluña había no menos de 100.000 afiliados. En 1881 cincuenta militantes barceloneses fundan también una federación obrera propia de origen anarquista, con 13.000 afiliados en Cataluña. A partir de ese momento se suceden los atentados, huelgas generales, incendios de iglesias y conventos, una etapa accidentada que culmina con el Proceso de Montjuïc y en la Semana Trágica, y cuyo telón de fondo, dice Vicens Vives, es un sentimiento de exasperación, mantenido vivo por las mujeres. Desde 1911, en que se funda la central anarco-sindicalista (Confederación General del Trabajo), hasta la Guerra Civil, será ésta quien domine todo el movimiento obrero.

Algunos intentaron luchar contra esta situación de la mujer. El segundo congreso de la Federación Española de la Primera Internacional, celebrado en Zaragoza el año 1872, y el Congreso de la Constitución Nacional de la Confederación del Trabajo se ocuparon particularmente de estos problemas.

Se dirá que el trabajo de la mujer es el origen de grandes inmoralidades, causa de la degeneración de la raza y que perturba las relaciones entre el capital y el trabajo en perjuicio de los trabajadores, por la concurrencia que les hacen las mujeres. A esto respondemos: la causa de estos males no está en el trabajo de las mujeres, sino en el monopolio que ejerce la clase explotadora. Transfórmese la propiedad individual en colectiva y se verá cómo cambia todo por completo... Entre tanto, creemos que nuestro trabajo acerca de la mujer es hacerla entrar en el movimiento obrero a fin de que contribuya a la obra común, al triunfo de nuestra causa, a la emancipación del proletariado, porque así como

38. M. A. Capmany, op. cit., p. 106. 
ante la explotación no hay diferencias, tampoco debe haberlas ante la justicia. ${ }^{39}$

Y más adelante:

Tenemos que considerar la disminución de horas de trabajo de las mujeres en las fábricas. Mientras tanto que muchos de nosotros permitimos que nuestras compañeras se levanten de la cama antes de las cinco de la mañana y nosotros permanecemos descansando. Y cuando la mujer acaba de derramar su sangre por espacio de doce horas para mantener los vicios de un explotador, llega a su casa y en lugar de descanso se encuentra con un nuevo burgués compañero, que con mayor tranquilidad espera que haga los quehaceres domésticos.

Las obreras españolas apenas tenían los medios de organizarse, ni disponían de tribunas para hacerse escuchar. $\mathrm{Y}$ sin embargo, numerosos documentos nos describen hasta qué punto estaban al lado de los hombres en la lucha y cómo a menudo les arrastraban a ella. En esta línea poseemos los testimonios y los escritos de algunas mujeres excepcionales, redactoras de periódicos revolucionarios, algunos de los cuales fueron genuinamente femeninos. Belén Segarra, por ejemplo, que participó en la constitución de una federación malagueña obrerista que agrupaba unas 60 sociedades con un total de 20.000 afiliadas, publica en Córdoba en 1902 una revista titulada Conciencia Libre, en colaboración con otras dos mujeres, Amalia Carvia y Soledad Arenales. Belén Segarra era además miembro de la Sociedad Libertaria de los Amigos del Progreso.

En 1902 aparece en Valencia una revista dirigida por mujeres y dedicada a ellas, Humanidad Libre, cuyos colaboradores más importantes eran Teresa Mañé («Soledad Gustavo»), Emma Goldman, Pedro Kropotkin, Federico Urales, Anselmo Lorenzo, Enrico Malatesta, F. Tarrida del Másmol. Se trata de una publicación muy bien realizada con gran abundancia de noticias concernientes a los conflictos obreros de toda España y artículos ideológicos que explican la teoría revolucionaria. He aquí algo de lo que allí se dice:

Venimos, en fin, como misión más esencial nuestra, a ocuparnos de la mujer, de esa pobre víctima, que a pesar de haber

39. Aberto Balcells, Trabajo industrial y organización obrera en Cataluña (Ba1: celona: Laia, 1974), p. 12. 
' sido cantada en mil tonos diversos y de haber sido idealizada y hermoseada por los poetas de todos los siglos, no ha dejado de ser la más ínfima de todas las víctimas, la más explotada y vilipendiada de todos los explotados. ${ }^{40}$

A propósito de la explosión de una caldera en una fábrica que mató a una gran cantidad de mujeres obreras y niñas de corta edad, Teresa Claramunt se expresa así:

Ya lo ves, mujer proletaria, nuestros hijos no inspiran a nadie ningún sentimiento noble, y nosotras las mujeres no pertenecemos al sexo débil, ya que se considera muy natural que recaiga sobre nosotras el trabajo pesado; no pertenecemos tampoco al sexo bello, porque auestros cuerpos destrozados no les despierta el sentimiento de justicia... Ya lo sabéis, obreras, en la sociedad actual existen dos castas, dos razas: la de nosotras y nuestros compañeros, y la de esos zánganos con toda su corte. No tendremos pan, ni dicha, ni vida, ni seguridad para nuestros seres queridos y para nosotras, hasta que desaparezca del todo esta maldita raza de parásitos. ¡A trabajar, pues, proletarias, nuestra dignidad y amor lo exige!

Esta Teresa Claramunt era una obrera textil de Sabadell y una de las pocas mujeres que llegó a hacer oír su voz en los mítines y arrastrar las obreras a la huelga. Estuvo en la cárcel y exilada varias veces. Pío Baroja cuenta como, embarazada, se golpeaba el vientre en un mitin y gritaba: « Este hijo no será un cobarde como vosotros!» En 1901 publicó, en colaboración con el anarquista Bonafulla, la revista El Productor y en un opúsculo intitulado La Mujer reivindicaba el derecho de ésta a participar en la vida política, social y económica, y la necesidad que tiene de tomar ella misma la iniciativa en su lucha contra la explotación en cuanto mujer y en cuanto obrera.

Soledad Gustavo, cuyo nombre verdadero era Teresa Mañé, era una maestra de escuela de un pueblo de Cataluña. Fue una de las principales colaboradoras de la Revista Blanca, portavoz del anarquismo en sus diversas manifestaciones flosóficas, artísticas y sociales, hasta la Guerra Civil. En noviembre de 1889 ganó el primer premio en un concurso celebrado

40. Lola Iturbe, La mujer en la lucha social (México: Ed. Mexicanos Unidos, S. A., 1974), p. 33. 
en el Palacio de Bellas Artes de Barcelona, con un ensayo titulado «El amor libre», del que extraemos el párrafo siguiente:

En una sociedad anarquista está igualada la relación de cualidades y de sexos, la fuerza no se impone a la libertad, pues ni el hombre es más fuerte con relación a la mujer, ni la mujer es más débil con relación al hombre. La Naturaleza libre y razonada como el sistema que la rige, con naturalidad y razón, da igualdad de armas a los dos sexos y a los dos les enseña el camino de sus derechos y de sus deberes. ${ }^{41}$

En 1899, con Juan Montseny, publica la revista Tierra y Libertad, suplemento de la Revista Blanca. Allí organiza la campaña por la defensa de los andaluces condenados en una revuelta agraria. Estamos lejos del mundo habitual en las revistas femeninas, lejos de las efusiones líricas sobre la maternidad y sus gozos, sobre la modestia y la caridad, lejos de la imagen de la mujer frágil, guardiana del hogar, objeto de adorno que un siglo de periodismo femenino se había cuidadosamente elaborado.

Pero la acción de estas mujeres revolucionarias y la de sus hijos durante las huelgas, revueltas campesinas, cuando participaban en los incendios de iglesias o se lanzaban a la calle a construir barricadas, horrorizaba las conciencias bien pensantes. Había que hacer alguna cosa para ayudar a la obrera cuya familia estaba abandonada en medio de la calle. Había que despertar la filantropía, impulsar la beneficencia. Si se remediaban aquellas necesidades hirientes educando a la obrera, encuadrándola en sociedades protectoras o patronatos de inspiración religiosa, se la alejaría de la actividad político-sindical y de su mente quedarían desarraigadas las ideas revolucionarias. De todo este programa se encargará en Cataluña la mujer de la burguesía, que se enrola, al lado de su marido, en la lucha políticoregionalista. Ellas crearán buen número de organizaciones para la defensa del orden, que, como dijo Margarita Nelken, más bien podría decirse «para defenderse del miedo»..., mientras que los patronos se niegan a respetar siquiera las leyes que reglamentan el trabajo de mujeres y niños, o que fijan el horatio a 11 horas.

$Y$ así, llegamos ahora a hablar del movimiento regionalista catalán, que va a promover esta política paternalista, y cuya prensa, en particular

41. Ibid., p. 45 . 
la prensa femenina que entonces adquiere una importancia especial, se hará eco. Los primeros pasos del catalanismo moderno habían sido los de un movimiento literario, lingǘstico, de un redescubrimiento de la lengua catalana y una nueva valoración de la misma como instrumento de expresión genuino. Es la Renaixença, cuyo símbolo social fueron los Jocs Florals, restablecidos en 1859. Hay un despertar de la conciencia colectiva de Cataluña que da un contenido nacionalista a la reacción suscitada por la amenaza librecambista y las crisis económicas y políticas en los años que siguen. Su oposición al gobierno central y la diferencia de estructura social entre la región catalana y el resto del país van a contribuir a polarizar esta corriente intelectual en un movirniento político que va a ser decisivo en la historia de ese pueblo.

Existe en la Cataluña del siglo XIx una alta burguesía industrial y banquera defensora del proteccionismo y la inversión, junto a una clase media trabajadora y liberal, a veces en situación económica precaria. En el resto de España, el agricultor cultiva la tierra para subsistir, no para vender; el noble va a la milicia o al convento, y el burgués de Madrid se dedica a la política o a la Administración. ${ }^{42}$

Poco a poco, «el orgullo de los intelectuales se une a los argumentos de los economistas y al descontento popular, y la solidaridad regional crece». ${ }^{43}$

Del regionalismo literario y lingüístico se pasa al autonomismo (1862, Bases de Manresa), y, luego de 1898, hasta se habla de nacionalidad. En 1906 la Solidaritat Catalana alcanza un gran triunfo electoral y el primer partido catalanista, la Lliga Regionalista, agrupa los elementos moderados de la alta burguesía industrial, los agricultores y comerciantes católicos y a la oposición de tipo democrático, pequeñoburguesa, de empleados, funcionarios e intelectuales. Esta clase media liberal se hace eco de todos los movimientos de vanguardia, de todas las novedades que provienen del resto de Europa. Se advierte en todas las revistas de moda o literarias un renacimiento de la actividad artística e intelectual y la influencia francesa e inglesa se hace sentir particularmente. Aquellas gentes creían en el progreso, tenían fe en el mundo moderno y, hasta cierto punto también, eran abiertos al feminismo. $Y$ así, la intervención de la mujer en la vida pública, en este ambiente de burguesía liberal abierto a las corrientes extranjeras, se producirá más fácilmente que en el resto de las regiones españolas, donde la mujer está, tradicionalmente, mucho más encerrada en su casa. Dolores Monserdá de Maciá es el portavoz de esta clase. Sus

42. P. Vilar, op. cit., p. 101.

43. Ibid., p. 101. 
primeros artículos nos hablan de la educación de las mujeres y del feminismo. Poetisa y costumbrista, denuncia a menudo los excesos de la alta sociedad, pero su ideología es conservadora, católica y fuertemente regionalista. Por necesidad, se preocupa de las luchas sociales y de la agitación obrera: «La mayoría de las mujeres obreras, víctimas de la agitación, cargadas de penas y humillaciones, de miserias y de lágrimas, soportan un calvario que es la vergüenza de la sociedad que lo consiente.» ${ }^{4}$

La opresión de los pobres reclama, en nombre de Dios, justicia, reparación y ayuda, mediante leyes, asociaciones y sindicatos que acaben con la explotación civilizada de la esclavitud blanca.

Pero,

... cambios radicales han obligado a las clases obreras a alterar su modo de vida. La mujer, hasta ahora reina del hogar por derecho natural, ha tenido que buscar fuera de su casa de qué vivir. Se ha puesto a competir con el hombre, se ha pervertido al lado de las masas obreras masculinas, sus hijos se quedan solos... En el fondo sólo la avidez desmesurada impulsa a la obrera fuera de su casa porque ahora ya no se contentan con una sopa y pan negro, sino que reclaman carne, caldo y pan blanco, cosas que sólo las familias ricas podían permitirse. ${ }^{45}$

Testigo presencial de los incendios de conventos e iglesias, Dolores Monserdá sintió la angustia y el pánico:

La participación de muchas mujeres en esos atentados es otro ejemplo de la ignorancia, que hace necesaria la acción de todas las mujeres catalanas en pro de una nueva orientación de la vida social. Hay que salir de la indiferencia y frivolidad en que nos movemos y realizar una serie de acciones que nos lleven a influir en una buena parte del proletariado barcelonés. ${ }^{45}$

Dolores Monserdá representa la mala conciencia de la cierecha, del reformismo burgués de la Lliga, cuyo portavoz es el semanario La Veu de p. 20.

44. M. A. Capmany, El feminisme a Catalunya (Barcelona: Nova Terra, 1973),

45. Ibid., pp. 39.40 .

46. Ibid., p. 44. 
Catalunya. Una extraña mezcla de gentes forman esta Lliga: «hombres malcasados que defienden la familia, incrédulos que defienden la Iglesia y pobres que defienden el Capital». ${ }^{47}$ El núcleo más avanzado de la Lliga fundó el periódico Joventut, una muestra magnífica de aquella Renaixença, y fuertemente influenciado por las corrientes modernistas. Estaba dirigido por Verdagué, Callís y Lluís Marsans, este último, personaje señalado de la Unió Catalanista. Sus artículos sobre la mujer obrera y la familia obrera tienen el mismo contenido ideológico que los de Dolores Monserdá. En Joventut participan numerosas mujeres, entre ellas Carme Karr, que escribe bajo el seudónimo de «L'Escargot». En 1902 aparece alli un artículo, «Per la dona catalana», que es un llamamiento a la mujer para que se integre en la lucha política y tome conciencia de su personalidad catalana: «iNecesitamos mujeres y las conseguiremos!» ${ }^{48}$ En el suplemento de Joventut leemos: « Adelante, mujeres catalanas, no nos abandonéis en la lucha!... ¡Continuad siendo hermosas! ¿Que la belleza y el amor sean vuestras virtudes supremas!» ${ }^{49}$ Una de las primeras actividades que se les asignó fue la ofrenda de una bandera catalana en el monasterio de Poblet.

En este estado de espíritu salió a la luz pública Or $i$ Grana, la primera revista femenina con intenciones políticas declaradas. Su subtítulo es expresivo: «Setmanari autonomista per a la dona. Propulsor d'una Lliga Patriòtica de Dames.» Se trata de una revista de 16 páginas, y a doble columna. Su primer número se publica el 6 de octubre de 1906.

Allí aparece esta proclama:

Nuestras manos, si no pueden llevar banderas al combate, pueden bordarlas; si no pueden defenderlas, pueden bendecirlas y pueden encomendarlas a Dios. La mujer, si no puede defender delante de los jueces, ni liberar un prisionero, puede dulcificarle la reclusión y puede incitar a los demás a que lo liberen. Aún más: la madre puede inducir al hijo a que quiera aquella bandera; la esposa puede excitar al esposo para que la defienda; la novia puede exigir del novio la promesa de seguirla. ${ }^{50}$

Su aparición mereció una "Glossa» de Eugeni d'Ors, que habla de la falta de sensibilidad artística de los hombres catalanes en contraste con la de las mujeres:

47. Ibid., p. 59.

48. Ibid., p. 60.

49. Ibid., p. 62.

50. Or i Grana, 1, octubre 1906, pp. 1-2. 
Recuerdo ahora este caso, en la alegría de tener entre los dedos este Or $i$ Grana, semanario para las mujeres, redactado para las mujeres. Hay en el artículo de presentación de este semanario un párrafo que comienza así: «En una mujer, un aplauso, una alabanza, un aliento, una adhesión, una mirada de simpatía o una sonrisa de recompensa valen...», yo me he quedado pensando en esto, en lo que valen, proveniendo de una mujer, el aplauso, el elogio, el aliento, frente a la obra de otro. Y pienso lo que podría resultar de otra función de crítica - de crítica por vez primera explícita- ejercida por las mujeres. ¿No sospecháis hasta qué punto podría ser práctica e ideal? ${ }^{\text {st }}$

El artículo termina con un saludo a las inteligentes redactoras de Or $i$ grana. Estas redactoras son Dolores Monserdá, Víctor Català, Carme Karr, Joaquima Rosal, Mercè Rodés, Maria Domènech de Canellas e Inés Armengol de Badía, entre otras. Las páginas ilustradas corren a cargo de dibujantes muy conocidos: Junceda, Bagaría, Apa, Muntaner, Opisso. Or i grana, aparte de su aire patriótico propio de aquel momento (1906 es, no lo olvidemos, el momento álgido de la Solidaritat Catalana), tenía un carácter francamente literario. La sección de poesía publicaba fragmentos de los mejores poetas catalanes: Apelles Mestres, Josep Carner, Xavier Gambús, Ferran Agulló, etc. Otra, titulada «De los hombres a las mujeres», hacía lugar a las intervenciones de numerosas personalidades literarias y políticas del momento.

A pesar de sus buenas intenciones patrióticas, se desencadenó una violenta campaña contra las redactoras de Or i grana, precisamente desde Joventut, campaña que dirigía Rafael Vallés. A las alabanzas que habían aparecido en La Veu de Catalunya, de la pluma de Eugeni d'Ors, responde que la mujer catalana no es capaz de criticar ni de crear nada decente; que esto quizá no sea tanto por culpa suya, sino de los hombres catalanes; que es una ignorante porque sus educadores - la escuela, el confesor y el marido, o el amante- le han dicho siempre que debía callarse y que Dios, sus padres y sus maridos pensarían por ellas; que leen sobre todo Blanco y Negro y que no dicen nada sustancioso.

Sin embargo, Or $i$ Grana no había hecho nada que pudiera provocar tal reacción; ni siquiera era una revista típicamente feminista y no se erigía en defensa de los derechos de la mujer. Era obvio, sin embargo, que poseía facultades y audiencia para desempeñar un papel político y realizar una

51. Citado por J. Torrens y R. Tasis, Història de la Premsa Catalana (Barcelona: Bruguera, 1966). 
campaña de proselitismo en pro de la misión de la mujer catalana en torno al partido político más importante del momento. Or i grana tomaba posiciones discretas en el debate de la oportunidad de la intervención de la mujer en política, limitando su papel a ser «el descanso del guerrero». Pero probablemente algunos hombres de la Solidaritat no las tenían todas consigo con respecto a esta intervención de la mujer, aun como colaboradora y sostén del hombre; menos aún si se trataba del derecho a votar, ya que se temían que, en nombre de la paz y de la tranquilidad, podían bloquear toda evolución y cambio.

Finaliza la aparición de Or i grana en febrero de 1907, después de 21 números. Sus redactoras dan un adiós momentáneo, según dicen, y manifiestan su firme intención de sacar una revista de mayor envergadura.

El 28 de abril de 1907 sale por vez primera, como suplemento mensual del semanario L'Ilustració Catalana, la revista prometida, que se titula Feminal. Su directora es Carme Karr, una de las principales figuras de Or $i$ grana. Escritora y pcetisa (uno de sus escritos fue premiado en los Juegos Florales de 1912), nacida de familia de escritores, asume enteramente su condición de intelectual. Carme Karr creía en la promoción de la mujer y estaba convencida de que le era necesaria una escuela y una educación que la situase en el mismo nivel intelectual que el hombre. Había que hacer bajar de su pedestal al omnipotente varón y colocar a su mismo nivel a la mujer, equilibrando ambas figuras. Feminal es una publicación dedicada a la mujer que ve la luz en un momento de euforia del catalanismo de los años 10. En el número 1 aparece en la portada un dibujo de Casas y en la primera página un retrato de $\mathrm{M}$. Josefa Massanes en daguerrotipo, homenaje a la primera mujer catalana que tuvo el valor de publicar sus obras.

Carme Karr dice en su artículo de presentación: «Nuestra finalidad es que Feminal vea en la mujer una amiga a quien hablaría en su lengua de todo lo que pudiera agradarle, despertando su interés por todo lo artístico, industrial y social del momento que vive.»

Feminal es realmente una revista femenina en el sentido que apenas se hace mención de política; su contenido lo forman artículos literarios, poesías, páginas de música, crónica social y narraciones breves. Tipográficamente era un alarde de lujo y buen gusto; tenía el mismo formato que L'Ilustració Catalana: veinte páginas con numerosos dibujos y fotografías y cada número tenía una magnífica cubierta ilustrada por Ramon Casas. La colaboración literaria corría a cargo de Dolores Monserdá, Inés Armengol de Badía, Víctor Català, la Condesa de Castellà y otras muchas. Esta promoción intelectual de la mujer era una fuerza que potenciaba la acción cultural y política catalanista, y los intelectuales catalanes, así como el 
grupo que financiaba L'Ilustració, eran bien conscientes de ello. "Queda por decir que iniciamos Feminal con el convencimiento de que venimos a llenar una de las necesidades más evidentes de nuestro Renacimiento.»

Carme Karr redactaba los artículos de fondo. En algunos de ellos, como los que tituló Consideracions, expresa sus proyectos y sus decepciones. Ella deseaba para la mujer una cultura, no de adorno, sino que le permitiera trabajar junto al hombre en pie de igualdad. Proponía abrir escuelas de aprendizaje, donde la mujer se preparase, mediante un oficio, a vivir independientemente.

A principios del año 1917, como consecuencia de las dificultades económicas ocasionadas por la Guerra Europea, la empresa editora de Feminal decidió reducir el formato de las publicaciones. Al finalizar el año las dificultades económicas eran aún mayores, y Feminal, en un artículo titulado «Adiós», dice que «para continuar publicando la revista habria que reducir de tal modo el número de páginas y aumentar el precio, que se ha decidido suspender la publicación». Habían salido en total 228 números, y el último fue el del 30 de diciembre de 1917.

Feminal reaparece en 1925. Sigue estando dirigido por Carme Karr, pero se ha tornado más independiente y está claramente politizado. Entonces es una revista bilingüe, editada por Acción Femenina. Desde alli se piden reformas legislativas, se presenta a las mujeres que desempeñan algún cargo político, se organizan conferencias en el Ateneo... Su existencia fue muy efímera.

Por su parte, las organizaciones eclesiásticas comienzan a darse cuenta de la importancia de la Prensa, y se desarrolla una fuerte campaña hacia, los años 1910-1920, en pro de una Prensa femenina católica. Acción Católico-Femenina, órgano de la Liga de Damas para la Acción Católica, publica tres largos artículos, firmados por el obispo de Jaca, sobre la necesidad de la colaboración femenina en la prensa. Ante todo, la necesidad de publicaciones de modas redactadas con un espíritu cristiano y en conformidad con los cánones de la modestia. Las actuales, dice el artículo, provocan la impureza y se hace sentir en ellas un aire de paganismo, una atmósfera muy diferente al buen olor de Cristo. Allí se propone una revista de modas en la que una costurera inglesa, preferentemente religiosa, publicaría, mediante retribución adecuada, diseños de moda prácticos, sencillos y decentes, que podrían ser adoptados por las señoras piadosas. Parece ser que el buen prelado desconfiaba hasta de las religiosas francesas, en lo que toca a la moda.

En otro artículo titulado "Periódicos de acción social femenina», el mismo obispo recomienda a las mujeres la vocación periodística. Ellas 
podrán, así, escribir sin salir incluso de casa, pues, dice, los periódicos mixtos son quizá tan peligrosos como las escuelas mixtas. ${ }^{52}$

En otro artículo precisa aún más su pensamiento:

Aun tratándose de asuntos no particularmente interesantes para las mujeres, convendrá que éstas escriban en los diarios católicos. La bienaventurada Juana de Arco peleaba entre los caballeros. ¿Qué inconveniente hay en que las damas cristianas, al ver en peligro los intereses más sagrados, empleen para la defensa de la causa de Dios los talentos con que las han distinguido, enviando sus producciones a los periódicos donde se Le da a conocer y se Le glorifica? ${ }^{53}$

Luego cita las diferentes revistas católicas femeninas como Jesús Maestro, publicada por las Teresianas; La Mujer Católica, órgano de la Obra de la Protección de los Intereses Católicos, y la Revista de las Hijjas de Maria.

Otra revista importante es La Mujer que vive de su trabajo, publicada por la Obra de Buenas Lecturas y Montepío de Santa Madrona, en colaboración con otras instituciones que se preocupan de las obreras. El objetivo de este periódico es constituirse en escuela de la mujer obrera «para hacerle bien y hacerla buena», lo cual, según Balmes, es el fin de toda propaganda. Distribuida gratuitamente, esta revistilla de pocas páginas es, por así decirlo, el primer órgano de la Acción Social Católica, en lo que concierne a la protección y ayuda a la obrera.

Después del fracaso de los círculos católicos que, a comienzos de siglo, habían esbozado un intento de gremialismo dirigido por el clero, la Acción Social Popular trata de crear una federación obrera católico-social, y organiza las Semanas Sociales de 1906, 1907 y 1908, durante las cuales se habla de la situación de las obreras que trabajan a domicilio y que constituían la minoría más explotada y la más oprimida dentro del conjunto de mujeres trabajadoras. Se trata de llamar la atención, especialmente, de las mujeres de la burguesía, pues eran ellas quienes tenían frecuentemente un trato personal con estas obreras que eran sus costureras, bordadoras, planchadoras o lavanderas. Su situación, sobre todo cuando trabajaban en talleres particulares, era aún peor si cabe que las de las obreras de la industria, pues era proverbial la falta de espacio, de ventilación, el cúmulo de horas que se veían obligadas a hacer y la irregularidad de la distribu-

52. Acción Católico-Femenina, 19, mayo 1913, pp. $12-13$.

53. Ibid., 24, septiembre-octubre 1913, p. 5. 
ción de su trabajo a lo largo del año. Procedentes de diversas clases sociales, les era prácticamente imposible asociarse porque trabajaban en grupos muy reducidos, medio ocultas y vergonzosas por tener que ganar así su vida. Aquellas mujeres, encima de no participar en el movimiento obrero, recibían los salarios más ínfimos de toda la industria y aún sufrían la competencia de las trabajadoras encuadradas en conventos y asilos de religiosas, las cuales recibían, a cambio de sus horas de trabajo, solamente comida. Todo ello en connivencia con las autoridades eclesiásticas, que en ningún momento permitieron que las asociaciones católicas hablaran de ello, o menos aún, controlasen el trabajo que se realizaba en este tipo de establecimientos.

El 10 de marzo de 1910 se fundó, bajo la protección del obispo, el Sindicato Barcelonés de la Aguja, un remedo de la asociación que bajo el mismo nombre funcionaba ya en Francia, en París y en Bordeaux. Sus fundadoras son Dolores Monserdá junto con otras damas de la burguesía. En 1911 es fundada por las señoras de Acción Católica, la Liga de Compradoras, que trata de poner en conocimiento de las clases medias, católicas y practicantes, la situación de aquellas mujeres que trabajaban para sus hogares. La Liga de Compradoras es la defensora encarecida del descanso dominical (propone el boicot de los tenderos que no lo observan) y del pronto pago de los trabajos que las señoras encargan. Por aquella época se funda igualmente el Institut de Cultura i Biblioteca Popular de la Dona. Lo dirige Francisca Bonnemaison de Verdaguer, viuda de Narcís Verdaguer, uno de los fundadores de la Lliga Regionalista, amigo de Prat de la Riba y colaborador de La Veu de Catalunya. El Institut de Cultura puede ser considerado como una de las obras de cultura populista del catalanismo conservador: allí se daban clases, casi enteramente gratuitas, de comercio, mecanografía, confección y trabajos domésticos. Varias publicaciones se hacen eco de las actividades del Institut, en particular Vida Femenina, patrocinada por la Caja de Pensiones para la Vejez y de Ahorros y que duró hasta 1936. La misma Caja de Pensiones, en 1922, montó, apoyada por la Lliga, el nuevo local de la Cultura, como se la llamaba en Barcelona. De acuerdo con esta entidad se creó una mutua para proteger del paro a las asociadas, así como una bolsa de trabajo.

En 1925 nace una revista de modas y hogar, Dona Catalana, que al principio publica los programas de actos del Institut de Cultura. Esta revista parece que tuvo bastante éxito y duró 12 años. Su editor la describe así: revista en que alterna lo útil con lo agradable: moda, confort, estética, sutileza, intimidad, novelas, música, sucesos curiosos...

En 1935 el Institut de Cultura tiene su propia revista mensual, $\mathrm{Cla}$ ror. Es una publicación lujosa de arte, cultura, decoración y modas. Ilus- 
trada con gusto, participan en ella escritores famosos y críticos literarios y de arte, pero carece de todo contenido político y social.

Por aquel tiempo, en Madrid también aparecen algunas revistas feministas, de las cuales la más importante es $\mathrm{La}$ Voz de la Mujer, portavoz del Instituto de Cultura de Madrid, del Liceum Club y de la Unión del Feminismo Español. Es, probablemente, la publicación que, dentro de su género, tuvo más importancia en España. Sus redactoras pretendieron formar un frente unido, apolítico y dedicado solamente a defender sus derechos femeninos sin distinción de clases ni ideologías. Esta posición es criticada dentro del mismo periódico por María Cambriles, socialista y autora de uno de los primeros libros feministas de carácter netamente político, Feminismo Socialista:

Nosotras, las mujeres socialistas, no tendríamos inconveniente en ir a este frente único que se nos propone si todos estos organismos que funcionan bajo la advocación de tal o cual santo, dirigidos por este o aquel otro cura, patrocinados por juntas de señoras de la aristocracia, o comunidades rezadoras, depusieran colectivamente, en aras de la libre acción femenina, aquella finalidad exclusiva de su agrupamiento. ¿Pero acaso cree, doña Celsia, que sería posible conseguir tal decisión de las mujeres, generalmente sugestionadas con las promesas de un más allá hipotético, que sólo se consagran para adorar santos y demandar mercedes a la divinidad? ${ }^{54}$

Celsia Regis le responde que su partidismo aleja a muchas mujeres de la causa femenina.

Gracias a esta revista, se celebra en Madrid el primer mitin feminista de España, en 1926. En él tomaron parte también las obreras junto con muchas mujeres que expresaron sus posiciones radicales y que habían preferido colaborar con La Voz de la Mujer antes que guardar silencio. Citemos tan sólo a Leonor Serrano de Xandrí, Clara Campoamor o María Espinosa, de quienes hablaremos en otro momento. Esta revista publicó también una entrevista con Primo de Rivera, en la que se declaraba feminista, y fue él quien otorgó 15. puestos a mujeres en la Asamblea Nacional

54. La Voz de la Mujer, citado por M. A. Capmany en Feminismo ibérico, op. cit., p. 37. 
y les dió acceso a los Consejos Municipales. Por el contrario, las declaraciones de Mussolini, que se preciaba de ser un feroz antifeminista, provocaron cierta confusión entre las redactoras de La Voz de la Mujer.

Otros periódicos feministas vieron la luz en Barcelona, Valencia y algunas otras ciudades españolas, entre 1915 y 1920, a la vez que proliferaban los organismos dedicados a la defensa de los derechos de la mujer, como: Mujeres del Porvenir, Progresiva Femenina, Liga Española para el Progreso de la Mujer, Sociedad Concepción Arenal, Asociación Nacional de Mujeres Españolas, Consejo Superior Feminista de España. Casi todos ellos tenían su publicación, pero éstas fueron efímeras. Citemos solamente Mujeres, Mujeres Españolas, Unión Femenina, de Barcelona. Esta última de orientación obrerista, aunque no vinculada a ningún partido.

A pesar del notable florecimiento literario y cultural que toma cuerpo en estos momentos en Cataluña, pocas revistas femeninas nuevas aparecen en Barcelona después de 1920. Con todo, es de señalar Lecturas, semanario de arte y literatura que nace en 1921 y sigue aún publicándose. Lecturas es el suplemento de El Hogar y la Moda, otra revista que ha resistido todas las vicisitudes económicas y políticas y que sigue aún en curso de publicación desde 1910. Su lectura nos ofrece un panorama fascinante de la evolución de la moda y del estilo de vida de la mujer de la burguesía en lo que va de siglo. Citemos, por último, La Mujer y el Cine, la primera revista de su género para mujeres.

Con el nacimiento de la República la prensa está cada vez más controlada por los partidos y sirve de tribuna de exposición de programas políticos precisos. Las revistas femeninas más significativas de este último periodo que precede la Guerra Civil, son: La Sembradora, emisario de la Juventud Católica Femenina. Es bilingüe (castellano y catalán). Su tono belicoso deja traslucir la tensa situación que vivía en estos momentos el catolicismo ibérico: la República es una amenaza contra la Iglesia, primero por la declaración de neutralidad religiosa del Estado con sus consecuencias políticas de enseñanza laica, matrimonio civil, divorcio, etcétera. Vendrán luego otras medidas más agresivas, como la disolución de la Compañía de Jesús y la confiscación de sus bienes en 1932. Y por último, la gota que hace desbordar el vaso, es la supresión del derecho a enseñar a las congregaciones religiosas. Por otra parte, la República ha concedido el voto a la mujer y la Iglesia se esfuerza en movilizar todo este potencial electoral. Todo esto se refleja en las páginas de la revista con una transparencia admirable. Algunos títulos de sus artículos dan una idea de ello: 
«La Mujer y el Cristianismo», «El matrimonio y el contrato civil», «La escuela laica contra los derechos de Dios, de los padres y de la Iglesia». En un momento dado, allí se hace referencia a una nueva organización política denominada Cívica Femenina, que se había creado para defender la religión católica y la libertad de la Iglesia, y que estaba en contra del divorcio, a favor de la enseñanza religiosa, no mixta, por la mejora de las condiciones sociales de los obreros y los sindicatos libres. El tono de $\mathrm{La}$ Sembradora es agresivo. Sus artículos de fondo nos sumergen en un mundo deprimente y opresivo, el de la opresión que ejerce la casta sacerdotal masculina sobre la mujer cristiana, encorsetándola en la piedad, la humildad, la paciencia, la mortificación. Sólo se habla de moda a contrapelo, para condenar de manera obsesiva la inmodestia en el vestir.

En la misma época ve la luz una nueva revista catalana, Evolució, quincenal y editada por la Liga Femenina por la Paz y la Libertad, una de las ramas de la sección femenina de la Lliga Catalana.

La entrada de las mujeres en la política era una consecuencia del artículo 32 de la Constitución de la República sobre la reforma de la Ley Electoral. El manifiesto de la sección femenina de la Lliga lo proclama en estos términos:

El deber de las mujeres ahora que tienen el derecho de votar, es de coordinar sus esfuerzos y sus actividades, de modo que sus intervenciones en la vida pública tengan el máximo grado de eficacia. Éstas deben quedar encuadradas dentro de los partidos existentes.

No obstante, la mayoría de las mujeres que participaban en la sección femenina de la Lliga no tuvieron acción política de ninguna índole, si bien ciertas tendencias se perfilan en el seno de la misma. Las más avanzadas (por decirlo de alguna manera) son las que asumen este programa y Evolució será su órgano y portavoz. Allí colaboran Margarita Nelken, diputado socialista por Badajoz, y autora del libro La condición social de la mujer en España, junto con Regina Opisso, Aurora Bertrán, Montserrat Graner y otras. Por desgracia, esta revista tuvo una vida corta también.

Encontraremos de nuevo alguna de sus colaboradoras en una revista curiosa, Bondat-Bonté, periódico literario y social redactado en catalán y en francés por la Unión Femenina Franco-Catalana. Su presentación dice así:

Por la módica suma de 15 céntimos las obreras podrán adquirir una revista seria y bien orientada, redactada en francés y en catalán y en la que las lectoras encontrarán páginas de cultura 
general, feminismo, deportes, consejos útiles. Todo estará escrito de manera decente, sin perder de vista el mensaje espiritual que queremos transmitir al pueblo.

Citaremos, finalmente, cinco revistas con las que culmina nuestro estudio de la prensa femenina española hasta 1939: Companya, Emancipación, Mujeres Libres, Mujeres (de Madrid, dirigida por Dolores Ibárruri) y Trabajadoras.

La primera es el portavoz del Partido Socialista Unificado catalán y aparece en febrero de 1937. Su subtítulo es elocuente por demás: «La libertad se lleva en la punta de las bayonetas.» Alli participan Margarita Nelken, La Pasionaria y Aurora Bertrán. Su programa es incorporar a las mujeres en todas las tareas del momento, sobre todo en la lucha militar. Se reclama: a igualdad de trabajo igualdad de salario, solución a los problemas de la prostitución, del cuidado de los niños y reformas legislativas. La presentación gráfica, en fotograbados a dos colores, es excelente. Da noticias de la guerra, adobadas con algunas recetas de cocina, hay una sección de crítica cinematográfica y novela por entregas.

Unas semanas antes, aparecía el periódico Emancipación, órgano de Secretariado Femenino del POUM (Partido Obrero de Unificación Marxista), que en uno de sus primeros editoriales se interroga a propósito de su «colega» Companya:

¿A qué mujer se dirige? ¿A la mujer burguesa que aún siente añoranza por aquellos tiempos cuando iba a tomar el té en cualquier café de moda? ¿O más bien a la mujer reformista que organiza manifestaciones contra los comités y que aprovecha las colas del pan para organizar «mueras» contra las organizaciones revolucionarias? ¿De cuál de estas mujeres es la revista? ${ }^{56}$

Ciertamente, las mujeres de Emancipación han tomado muy en serio su misión. Aquí no hay ni rastro de recetas culinarias, ni de crítica literaria; es la lucha escueta por la revolución social, es la emancipación de la mujer proletaria que reclama una vez más sus derechos (incluso ahora, frente a su ibérico compañero marxista). La correspondencia de las lectoras es sumamente interesante: las obreras exponen alli sus problemas, piden soluciones de manera muy sencilla y realista; aquí ya no hay palabras

55. Bondat-Bonté, 1.

56. Emancipación, 1, enero 1937. 
complicadas y teorías, sino hechos concretos expresados en un lenguaje directo.

Mujeres Libres, que hemos reservado para el último lugar a pesar de que su fecha de aparición (abril de 1936) es anterior a la de Companya y Emancipación, nos parece la más importante de todas.

Fue creada por un grupo de mujeres anarquistas que formaron una organización también anarquista y que trabajaron a veces en colaboración con las de Emancipación, el único grupo que no entró en conflicto con ellas. La revista publicó trece números en foto-litografía. La empresa editora y la imprenta estaban colectivizadas. La organización del grupo también estaba descentralizada y en estrecha relación con los otros grupos anarquistas locales. Fue, con mucho, la agrupación femenina que mejor funcionó. Tres fueron las fundadoras de la revista: Lucía Sánchez Saornil, una joven empleada de la Telefónica, afiliada muy pronto a la CNT y que también colabora asiduamente en periódicos anarquistas y anarco-sindicalistas como Solidaridad Obrera, La Revista Blanca, Tiempos Nuevos, Umbral; Amparo Bosch Gascón, que era doctor en Medicina, y Mercedes Camposada, ambas igualmente redactoras de La Revista Blanca y de Tierra y Libertad.

Poco a poco, el grupo fue creciendo y en septiembre del mismo año se celebraron dos asambleas de «Mujeres Libres», una en Barcelona y otra en Madrid. Al año siguiente se cuentan 147 asambleas, con más de 20.000 afiliadas, en su mayoría obreras. En agosto de 1937 se celebra el primer Congreso Nacional y se constituye la Federación Nacional de $\mathrm{Mu}$ jeres Libres. Para la revista se trataba de hacer tomar conciencia a la mujer obrera de su situación de oprimida, en cuanto mujer y en cuanto trabajadora. A los sectores menos instruidos se les distribuían pequeños opúsculos en donde se les explicaba todo esto de manera muy sencilla, y también hubo el proyecto de un semanario, con el título de Lucbadoras, destinado a las mujeres del campo.

Mujeres Libres era una revista de contenido muy variado. Allí se pone en cuestión todo el sistema de relaciones tradicionales entre hombres y mujeres, y entre éstas y los niños; aboga por una maternidad consciente, programas de educación sexual y libertad para abortar; se difunden nuevas ideas sobre puericultura e higiene y nuevas concepciones de la educación. Se plantean los problemas de la adaptación al trabajo y de formación profesional, incluso se ataca la división del trabajo y la separación tradicional de roles entre el hombre y la mujer. También se discuten los problemas de organización política y los conflictos con los otros partidos. Las reivindicaciones y peticiones de las lectoras eran escuchadas. La revista publicó, asimismo, un romancero de la mujer libre y poesías y cantos.

Para aquellas mujeres se trataba, evidentemente, de ganar el mayor 
número posible de sus iguales a la causa de la guerra. Imbuidas de la ideología del Frente Popular, según la cual no podía darse ningún cambio real en su vida personal sino con la victoria de la guerra, concentraron todos sus esfuerzos de organización para este fin. Pero, además, creían que la revolución económica y social no tenía por qué esperar la victoria de las armas, y esto les acarreó varios conflictos con los demás partidos revolucionarios. Igualmente, sostenían que la mujer no podía tener conciencia de su problemática más que con la ayuda de movimientos específicamente femeninos (cosa que Teresa Claramunt ya había proclamado en 1905), pero también aquí se separaban de las posiciones que habían adoptado al respecto la CNT y la FAI, organizaciones que, por otra parte, no poseían ningún programa concreto para ayudar a la mujer a conseguir su autoemancipación y su liberación como mujer y como trabajadora. En una palabra, la revolución social sin la emancipación social de la mujer no tenía sentido para Mujeres Libres, y la emancipación de la mujer era imposible sin una ardua lucha social que debían protagonizar las propias mujeres. Estamos muy lejos del feminismo de Dolores Monserdá, de Celsia Regis o del de Francisca de Bonnemaison. Estamos por primera vez -y también por última- delante de un proyecto de participación colectiva al esfuerzo colosal de las trabajadoras españolas para lograr su emancipación psicológica y social. 